\title{
Nonlinear Free and Forced Vibration Behavior of Shear-Deformable Composite Beams with Shape Memory Alloy Fibers
}

\author{
Ren Yongsheng, Du Chenggang, and Shi Yuyan \\ College of Mechanical and Electronic Engineering, Shandong University of Science and Technology, Qingdao 266510, China \\ Correspondence should be addressed to Ren Yongsheng; rys56@sohu.com
}

Received 21 March 2016; Accepted 6 June 2016

Academic Editor: Ivo Caliò

Copyright (C) 2016 Ren Yongsheng et al. This is an open access article distributed under the Creative Commons Attribution License, which permits unrestricted use, distribution, and reproduction in any medium, provided the original work is properly cited.

\begin{abstract}
The nonlinear free and forced vibration of the composite beams embedded with shape memory alloy (SMA) fibers are investigated based on first-order shear deformation beam theory and the von Kármán type nonlinear strain-displacement equation. A thermomechanical constitutive equation of SMA proposed by Brinson is used to calculate the recovery stress of the constrained SMA fibers. The equations of motion are derived by using Hamilton's principle. The approximate solution is obtained for vibration analysis of the composite beams based on the Galerkin approach. The parametric study is carried out to display the effect of the actuation temperature, the volume fraction, the initial strain of SMA fibers, and the length-to-thickness ratio. The shear deformation is shown to have a significant contribution to nonlinear vibration behavior of the composite beams with SMA fibers.
\end{abstract}

\section{Introduction}

In the last two decades much progress has been made on the research of shape memory alloy (SMA) composite structures. By the design of the smart composite structures with highly integrated SMA actuators, the vibration control of complex flexible structures with rigorous weight limitations such as aerostructures has become possible. SMA is able to generate a relatively large deformation at a low temperature, but deformed SMA will return to their original shape upon heating. Prestrained SMA fibers are embedded within composite structures. When an electric current passes through SMA fibers, resistance heat is generated in the fibers and a large internal force is induced into the structures due to the return of fibers to their original shape. The force induced and the change in the mechanical properties of SMA fibers can be used in improving deflection, buckling, flutter, and vibration characteristics of composite structures.

Zou [1] derived the incremental finite element motion equation for the nonlinear composite laminate embedded with SMA fibers, and the bending, thermobuckling, and postbuckling for the SMA reinforced composite laminate under transverse loading were discussed. Linear and nonlinear flutter behaviors of SMA reinforced composite laminates were studied by Kuo et al. [2] employing finite element method and approximate data from the SMA curves. Park et al. [3, 4] presented the finite element model for nonlinear flutter and vibration of composite laminates plates by using the approximate experimental fitting of SMA. Li et al. [5] studied free vibration of thermally pre/postbuckled circular thin plates with embedded SMA fibers. Shiau et al. [6] investigated the effect of SMA on the free vibration behavior of buckled cross-ply and angle-ply laminates by varying the SMA fiber spacing using the finite element method. Ren and Sun [7] investigated large amplitude flexural vibration of the orthotropic composite plate with embedded SMA fibers using the Galerkin approximate and harmonic balance methods. Asadi et al. [8,9] investigated nonlinear free vibration, primary/secondary resonance, and thermal postbuckling of SMA fiber reinforced hybrid composite beams with symmetric and asymmetric layup; nonlinear von Kármán strain field was employed.

However, most of the previous studies were performed based on finite element modeling of the geometric nonlinear structures $[1-4,6]$. It can be seen that few researches presented analytical solutions for vibration analysis of SMA 
composite plates and beams accounting for the shear deformation. Furthermore, it is found that the thermomechanical behavior was described by the expression of approximate fitting or use of the approximate data obtained from the curves of SMA $[2-4,6]$.

The objective of this work is to present a framework for analyzing smart composite beams with integral SMA active fibers for meeting the specific design requirements of the slender beam-like structures in aerospace and mechanical engineering structures, such as airplane wings and automotive drive shafts.

The present analysis extends the previous work done for large amplitude vibration modeling of passive laminated composite beam with axially immovable ends $[10,11]$. It also extends the closed-form solution of SMA fiber reinforced hybrid composite beams formulation presented by Asadi et al. [8] by taking into account the effects of the transverse shear. The resulting model is expected to correctly predict the dynamical behavior of for moderately thick and thick composite beams, accounting for the presence of SMA active fibers.

In the current work, an analytical solution is presented to study the large amplitude vibration of composite beams with embedded SMA fibers. The one-dimensional constitutive equation of SMA proposed by Brinson [12] is used to calculate the recovery stress generated with SMA fibers. The firstorder shear deformation beam theory and the von Kármán strain geometric nonlinearity as well as Hamilton's principle are utilized to derive the nonlinear governing equations of motion. Using an analytical approach based on the Galerkin method, a closed-form solution of governing equations is derived. The closed-form solution is then applied to nonlinear free and forced vibration analysis of the composite beams. The parametric study is carried out to display the effect of the actuation temperature, the volume fraction, the initial strain of SMA fibers, and the length-to-thickness ratio. The shear deformation is shown to have a significant contribution to nonlinear vibration behaviors of the composite beams.

\section{Formulations}

The equations of motion for composite beams with embedded SMA fibers are obtained using the Hamilton principle, which is

$$
\int_{t_{1}}^{t_{2}}\left(\delta V+\delta W_{\mathrm{nc}}-\delta T\right) d t=0
$$

where $\delta V, \delta T$, and $\delta W_{\mathrm{nc}}$ denote the virtual strain energy, the virtual kinetic energy, and the virtual work done by nonconservative forces, respectively.

The strain energy is

$$
V=\frac{1}{2} \int_{0}^{L} \int_{A}\left(\sigma_{x} \varepsilon_{x}+\tau_{x z} \gamma_{x z}\right) d A d x
$$

TABLE 1: The shape function for different beam theories.

\begin{tabular}{lc}
\hline Beam theory & $f(z)$ \\
\hline Euler-Bernoulli & 0 \\
Timoshenko & $\mathrm{z}$ \\
\hline
\end{tabular}

The strain-displacement equations considering von Kármán type of geometric nonlinearity and shear deformation can be written as

$$
\begin{aligned}
\varepsilon_{x} & =\bar{\varepsilon}+z \bar{\kappa}+f(z) \frac{\partial u_{1}}{\partial x}, \\
\gamma_{x z} & =\frac{\partial f}{\partial z} u_{1},
\end{aligned}
$$

where

$$
\begin{aligned}
& \bar{\varepsilon}=\frac{\partial u}{\partial x}+\frac{1}{2}\left(\frac{\partial w}{\partial x}\right)^{2}, \\
& \bar{\kappa}=-\frac{\partial^{2} w}{\partial x^{2}} .
\end{aligned}
$$

Here, $u_{1}$ are unknown displacement functions of the midplane; $f(z)$ is a shape function describing the shear deformation across the thickness [10].

The function $f(z)$ obtained from different beam theories is presented in Table 1.

The off-axis stress-strain relation of SMA fibers hybrid lamina has the following forms [13]:

$$
\begin{aligned}
\left(\sigma_{x}\right)_{k} & =\bar{Q}_{11} \varepsilon_{x}-\bar{Q}_{11}^{c} \alpha_{x}^{c} \Delta T+m^{2} V_{s} \sigma^{r}, \\
\left(\tau_{x z}\right)_{k} & =\bar{Q}_{55} \gamma_{x z},
\end{aligned}
$$

where $\sigma^{r}$ denotes the effective recovery stress of SMA fiber which is obtained based on the one-dimensional model of SMA proposed by Brinson [12].

The thermal expansion coefficients $\alpha_{x}^{c}$ in (5) is given by

$$
\alpha_{x}^{c}=m^{2} \alpha_{1}^{c}+n^{2} \alpha_{2}^{c}
$$

where $\alpha_{1}^{c}$ and $\alpha_{2}^{c}$ are the thermal expansion coefficient of the composite medium. $m$ and $n$ are the cosine and sine functions of the ply angle in each lamina, respectively. Also the off-axis stiffnesses can be expressed as $\bar{Q}_{11}=Q_{11} m^{4}+$ $2\left(Q_{12}+2 Q_{66}\right) m^{2} n^{2}+Q_{22} n^{4}, \bar{Q}_{55}=m^{2} Q_{44}+n^{2} Q_{55}$, and $\bar{Q}_{11}^{c}=Q_{11}^{c} m^{4}+2\left(Q_{12}^{c}+2 Q_{66}^{c}\right) m^{2} n^{2}+Q_{22}^{c} n^{4}$. 
The in-axis stiffnesses can be written as

$$
\begin{aligned}
& Q_{11}^{c}=\frac{E_{1 m}}{1-v_{12 m} \nu_{21 m}}, \\
& Q_{12}^{c}=\frac{\nu_{21 m} E_{2 m}}{1-v_{12 m} \nu_{21 m}}, \\
& Q_{21}^{c}=\frac{\nu_{12 m} E_{1 m}}{1-\nu_{12 m} \nu_{21 m}}, \\
& Q_{22}^{c}=\frac{E_{2 m}}{1-v_{12 m} \nu_{21 m}}, \\
& Q_{66}^{c}=G_{12 m}, \quad v_{21 m} E_{2 m}=v_{12 m} E_{1 m}, \\
& Q_{11}=\frac{E_{1}}{1-v_{12} \nu_{21}} \\
& Q_{12}=\frac{\nu_{21} E_{2}}{1-v_{12} \nu_{21}} \\
& Q_{21}=\frac{v_{12} E_{1}}{1-v_{12} \nu_{21}} \\
& Q_{22}=\frac{E_{2}}{1-\nu_{12} \nu_{21}}, \\
& Q_{66}=G_{12}, \quad v_{21} E_{2}=v_{12} E_{1} .
\end{aligned}
$$

$$
\sigma_{r}= \begin{cases}\Theta\left(T-T_{0}\right)+\sigma_{0}, & 0 \leq T \leq A_{s}^{\sigma} \\ E(\xi) \varepsilon_{0}-E\left(\xi_{0}\right) \varepsilon_{0}+\Omega(\xi) \xi_{s}-\Omega\left(\xi_{0}\right) \xi_{s 0}+\Theta\left(T-A_{s}^{\sigma}\right)+\sigma_{1}, & A_{s}^{\sigma} \leq T \leq A_{f}^{\sigma} \\ \Theta\left(T-A_{f}^{\sigma}\right)+\sigma_{2}, & T \geq A_{f}^{\sigma},\end{cases}
$$

during cooling

$$
\sigma_{r}= \begin{cases}\Theta\left(T-A_{f}^{\sigma}\right)+\sigma_{2}, & M_{s}^{\sigma} \leq T \leq A_{f}^{\sigma} \\ E(\xi) \varepsilon_{0}-E\left(\xi_{0}\right) \varepsilon_{0}+\Omega(\xi) \xi_{s}+\Theta\left(T-M_{s}^{\sigma}\right)+\sigma_{3}, & M_{f}^{\sigma} \leq T \leq M_{s}^{\sigma},\end{cases}
$$

where $\xi$ denotes the martensite fraction, $E(\xi)$ denotes the elastic modulus of SMA, $\Theta$ denotes the thermal elastic modulus, $T$ denotes temperature and $T_{0}$ is the reference temperature, and $\Omega(\xi)$ denotes the phase transformation coefficient. The subscript 0 denotes initial state. $A_{s}^{\sigma}$ and $A_{f}^{\sigma}$ denote the start and finish temperatures of austenite in stress, and $M_{s}^{\sigma}$ and $M_{f}^{\sigma}$ denote the start and finish temperatures of martensite in stress. $\xi_{s}$ is the martensite
The material properties of the composite beams embedded with SMA fibers can be written as

$$
\begin{aligned}
E_{1} & =E_{1 m} V_{m}+E_{s} V_{s}, \\
E_{2} & =\frac{E_{2 m} E_{s}}{\left[E_{2 m} V_{s}+E_{s} V_{m}\right]}, \\
G_{12} & =G_{13}=\frac{G_{12 m} G_{s}}{\left[G_{12 m} V_{s}+G_{s} V_{m}\right]}, \\
G_{23} & =G_{23 m} V_{m}+G_{s} V_{s}, \\
G_{s} & =\frac{E_{s}}{2\left(1+v_{s}\right)}, \\
v_{12} & =v_{12 m} V_{m}+v_{s} V_{s}, \\
\rho & =\rho_{m} V_{m}+\rho_{s} V_{s}, \\
V_{m}+V_{s} & =1,
\end{aligned}
$$

where the subscripts $m$ and $s$ denote the composite matrix and SMA fiber, respectively. The parameters $E, G, v, \rho$, and $V$ are Young's modulus, the shear modulus, Poisson's ratio, the material density, and the volume fraction, respectively.

Using the one-dimensional SMA constitutive equation developed by Brinson [12], the expressions for the recovery stress of SMA fibers during heating and cooling can be, during heating 
The transformation process from martensite to austenite $(M \rightarrow A)$ and from austenite to martensite are given, respectively, as follows $(A \rightarrow M)$ :

$$
\begin{aligned}
& \xi_{M \rightarrow A}=\frac{\xi_{s 0}}{2}\left\{\cos \left[\frac{\pi}{A_{f}-A_{s}}\left(T-A_{s}-\frac{\sigma^{r}}{C_{A}}\right)\right]+1\right\}, \\
& \xi_{A \rightarrow M}=\frac{1-\xi_{s 0}}{2} \\
& \cdot \cos \left\{\frac{\pi}{\sigma_{s}^{c r}-\sigma_{f}^{c r}}\left[\sigma^{r}-\sigma_{f}^{c r}-C_{M}\left(T-M_{s}\right)\right]\right\} \\
&+\frac{1+\xi_{s 0}}{2}
\end{aligned}
$$

where $M_{s}$ and $M_{f}$ are the start and finish temperature points during the phase transformation from austenite to martensite and $A_{s}$ and $A_{f}$ are the start and finish temperature points during the phase transformation from martensite to austenite, respectively. $C_{A}$ and $C_{M}$ are material constant of SMA fibers. $\sigma_{s}^{c r}$ and $\sigma_{f}^{c r}$ are the start and finish stress points of phase transformation, respectively.

In (9) and (10), $\sigma_{1}$ and $\sigma_{2}$ are the start and finish stress for the transformation $(M \rightarrow A) ; \sigma_{3}$ is the start stress for the transformation $(A \rightarrow M)$.

$\sigma_{1}, \sigma_{2}$, and $\sigma_{3}$ can be determined as follows:

$$
\begin{aligned}
\sigma_{1} & =\Theta\left(A_{s}^{\sigma}-T_{0}\right)+\sigma_{0}, \\
\sigma_{2} & =\sigma_{1}+E_{A} \varepsilon_{0}-E\left(\xi_{0}\right) \varepsilon_{0}-\Omega\left(\xi_{0}\right) \xi_{s 0}+\Theta\left(A_{f}^{\sigma}-A_{s}^{\sigma}\right) \\
\sigma_{3} & =\sigma_{2}+\Theta\left(M_{s}^{\sigma}-A_{f}^{\sigma}\right), \\
A_{s}^{\sigma}= & \frac{a_{A} A_{s}-b_{A} \sigma_{0}+b_{A} \Theta T_{0}}{a_{A}+\Theta b_{A}}, \\
A_{f}^{\sigma}= & \frac{a_{A} A_{s}-b_{A} \sigma_{1}-b_{A} E_{A} \varepsilon_{0}+b_{A} E\left(\xi_{0}\right) \varepsilon_{0}+b_{A} \Omega\left(\xi_{0}\right) \xi_{s 0}+b_{A} \Theta A_{s}^{\sigma}+\pi}{a_{A}+b_{A} \Theta}, \\
M_{s}^{\sigma}= & \frac{\sigma_{2}-\sigma_{s}^{c r}+C_{M} M_{s}-\Theta A_{f}^{\sigma}}{C_{M}-\Theta}, \\
M_{f}^{\sigma}= & \frac{\sigma_{3}-\sigma_{f}^{c r}+E\left(\xi_{0}\right) \varepsilon_{0}-E_{A} \varepsilon_{0}+\Omega\left(\xi_{0}\right) \xi_{s 0}-\Theta M_{s}^{\sigma}+C_{M} M_{s}+\left(\left(\sigma_{f}^{c r}-\sigma_{s}^{c r}\right) / \pi\right) \arccos \left(2 \xi_{0}-1\right)}{C_{M}-\Theta} .
\end{aligned}
$$

The elastic modulus $E_{s}(\xi)$ and the phase transformation coefficient $\Omega(\xi)$ can be expressed, respectively, as

$$
\begin{aligned}
& E(\xi)=E_{A}+\xi\left(E_{M}-E_{A}\right), \\
& \Omega(\xi)=-\varepsilon_{L} E(\xi),
\end{aligned}
$$

where $E_{M}$ and $E_{A}$ are Young's modulus in the martensite and austenite phase, respectively, and $\varepsilon_{L}$ is recovery strain limit.

Substituting (3)-(5) into (2) results in

$$
V=\frac{1}{2} \int_{0}^{L}\left(N \bar{\varepsilon}+M \bar{\kappa}+M_{s} \frac{\partial u_{1}}{\partial x_{1}}+Q_{s} u_{1}\right) d x
$$

where the following stress resultants are introduced:

$$
\begin{aligned}
N & =\int_{A} \sigma_{x} d A, \\
M & =\int_{A} \sigma_{x} z d A, \\
M_{s} & =\int_{A} \sigma_{x} f d A, \\
Q_{s} & =\int_{A} \tau_{x z} \frac{\partial f}{\partial x} d A .
\end{aligned}
$$

Here $N$ and $M$ are the axial force and moment stress resultants; $Q_{s}$ and $M_{s}$ are stress resultants associated with the shear deformation. Using the stress-strain relation of the 
SMA reinforced lamina, the stress resultants can be expressed in terms of the strains as follows:

$$
\begin{aligned}
& \left(\begin{array}{c}
N \\
M \\
M_{s}
\end{array}\right)=b\left(\left[\begin{array}{lll}
A_{11} & B_{11} & E_{11} \\
B_{11} & D_{11} & F_{11} \\
E_{11} & F_{11} & H_{11}
\end{array}\right]\left(\begin{array}{c}
\bar{\varepsilon} \\
\bar{\kappa} \\
u_{1}^{\prime}
\end{array}\right)-\left(\begin{array}{c}
N^{T} \\
M^{T} \\
M_{s}^{T}
\end{array}\right)\right. \\
& \left.\quad+\left(\begin{array}{c}
N^{r} \\
M^{r} \\
M_{s}^{r}
\end{array}\right)\right), \\
& Q_{s}=b A_{55} u_{1},
\end{aligned}
$$

where

$$
\begin{aligned}
\left(A_{11}, B_{11}, D_{11}\right) & =\sum_{k=1}^{n} \int_{h_{k-1}}^{h_{k}} \bar{Q}_{11}\left(1, z, z^{2}\right) d z, \\
\left(E_{11}, F_{11}, H_{11}\right) & =\sum_{k=1}^{n} \int_{h_{k-1}}^{h_{k}} \bar{Q}_{11}\left(f, f z, f^{2}\right) d z, \\
A_{55} & =\sum_{k=1}^{n} \int_{h_{k-1}}^{h_{k}} \bar{Q}_{55}\left(\frac{\partial f}{\partial x}\right)^{2} d z, \\
\left(N^{T}, M^{T}, M_{s}^{T}\right) & =\sum_{k=1}^{n} \int_{h_{k-1}}^{h_{k}} \bar{Q}_{11}^{c} \alpha_{x} \Delta T(1, z, f) d z, \\
\left(N^{r}, M^{r}, M_{s}^{r}\right) & =\sum_{k=1}^{n} \int_{h_{k-1}}^{h_{k}} m^{2} V_{s} \sigma^{r}(1, z, f) d z .
\end{aligned}
$$

Here, the superscripts " $T$ " and " $r$ " refer to the in-plane forces and moments induced by temperature and recovery stress of SMA fibers, respectively.

By using (4), the variation of the strain energy (16) can be written as

$$
\begin{aligned}
\delta V & =\int_{0}^{L}\left\{-\frac{\partial N}{\partial x} \delta u-\left[\frac{\partial}{\partial x}\left(N \frac{\partial w}{\partial x}\right)+\frac{\partial^{2} M}{\partial x^{2}}\right] \delta w\right. \\
& \left.+\left(Q_{s}-\frac{\partial M_{s}}{\partial x}\right) \delta u_{1}\right\} d x .
\end{aligned}
$$

The kinetic energy of the composite beam can be expressed as

$$
\begin{aligned}
T & =\frac{1}{2} \int_{0}^{L} \int_{A} \rho\left(\dot{U}^{2}+\dot{W}^{2}\right) d A d x \\
& =\frac{b}{2} \int_{0}^{L} \int_{-h / 2}^{h / 2} \rho\left[\left(\dot{u}-z \frac{\partial \dot{w}}{\partial x}+f \dot{u}_{1}\right)^{2}+\dot{w}^{2}\right] d z d x
\end{aligned}
$$

where the dot denotes differentiation with respect to time.
The variation of the kinetic energy (21) is given as

$$
\begin{aligned}
\delta T & =-b \int_{0}^{L}\left[\left(m_{1} \ddot{u}-m_{2} \frac{\partial \ddot{w}}{\partial x}+m_{4} \ddot{u}_{1}\right) \delta u\right. \\
& +\left(m_{1} \ddot{w}+m_{2} \frac{\partial \ddot{u}}{\partial x}-m_{3} \frac{\partial^{2} \ddot{w}}{\partial x^{2}}+m_{5} \frac{\partial \ddot{u}_{1}}{\partial x}\right) \delta w \\
& \left.+\left(m_{4} \ddot{u}-m_{5} \frac{\partial \ddot{w}}{\partial x}+m_{6} \ddot{u}_{1}\right) \delta u_{1}\right] d x,
\end{aligned}
$$

where

$$
\begin{aligned}
& m_{1}=\sum_{k=1}^{n} \int_{h_{k-1}}^{h_{k}} \rho d z, \\
& m_{2}=\sum_{k=1}^{n} \int_{h_{k-1}}^{h_{k}} \rho z d z, \\
& m_{3}=\sum_{k=1}^{n} \int_{h_{k-1}}^{h_{k}} \rho z^{2} d z, \\
& m_{4}=\sum_{k=1}^{n} \int_{h_{k-1}}^{h_{k}} \rho f d z, \\
& m_{5}=\sum_{k=1}^{n} \int_{h_{k-1}}^{h_{k}} \rho f z d z, \\
& m_{6}=\sum_{k=1}^{n} \int_{h_{k-1}}^{h_{k}} \rho f^{2} d z .
\end{aligned}
$$

The work done by nonconservative forces can be given as

$$
W_{\mathrm{nc}}=-b \int_{0}^{L} q w d x,
$$

where $q$ is the out-of-plane mechanical load.

Applying Hamilton principle leads to the following equations of motion:

$$
\begin{aligned}
& m_{1} \ddot{u}-m_{2} \frac{\partial \ddot{w}}{\partial x}+m_{4} \ddot{u}_{1}-\frac{1}{b} \frac{\partial N}{\partial x}=0, \\
& m_{1} \ddot{w}+m_{2} \frac{\partial \ddot{u}}{\partial x}-m_{3} \frac{\partial^{2} \ddot{w}}{\partial x^{2}}+m_{5} \frac{\partial \ddot{u}_{1}}{\partial x} \\
& -\frac{1}{b}\left[\frac{\partial}{\partial x}\left(N \frac{\partial w}{\partial x}\right)+\frac{\partial^{2} M}{\partial x^{2}}\right]=q, \\
& m_{4} \ddot{u}-m_{5} \frac{\partial \ddot{w}}{\partial x}+m_{6} \ddot{u}_{1}+\frac{1}{b} Q_{s}-\frac{1}{b} \frac{\partial M}{\partial x}=0 .
\end{aligned}
$$


The simplified nonlinear governing equations can be obtained from (25) by setting the in-plane inertia and rotational terms equal to zero.

The resulting equations are

$$
\begin{aligned}
\frac{\partial N}{\partial x} & =0, \\
m_{1} \ddot{w}+m_{5} \frac{\partial \ddot{u}_{1}}{\partial x}-\frac{1}{b}\left[\frac{\partial}{\partial x}\left(N \frac{\partial w}{\partial x}\right)+\frac{\partial^{2} M}{\partial x^{2}}\right] & =q, \\
m_{6} \ddot{u}_{1}+\frac{1}{b} Q_{s}-\frac{1}{b} \frac{\partial M}{\partial x} & =0 .
\end{aligned}
$$

From the first equation of (26), it is evident that the axial force $N$ is a constant, which means that the following equation holds:

$$
\begin{aligned}
& \frac{\partial N}{\partial x}=\frac{\partial}{\partial x}\left\{A_{11}\left[\frac{\partial u}{\partial x}+\frac{1}{2}\left(\frac{\partial w}{\partial x}\right)^{2}\right]-B_{11} \frac{\partial^{2} w}{\partial x^{2}}\right. \\
& \left.+E_{11} \frac{\partial u_{1}}{\partial x}-N^{T}+N^{r}\right\}=0 .
\end{aligned}
$$

Integrating (27) along the $x$-axis yields

$$
\begin{aligned}
u= & -\frac{1}{2} \int_{0}^{x}\left(\frac{\partial w}{\partial x}\right)^{2} d x+\frac{B_{11}}{A_{11}} \frac{\partial w}{\partial x}-\frac{E_{11}}{A_{11}} u_{1} \\
& +\frac{1}{A_{11}}\left(N^{T}-N^{r}+C_{1}\right) x+C_{2} .
\end{aligned}
$$

Using the in-plane boundary conditions $u(0, t)=$ $u(L, t)=0$ in (28), the constants $C_{1}$ and $C_{2}$ can be determined as

$$
\begin{aligned}
C_{1}= & \frac{A_{11}}{2 L} \int_{0}^{L}\left(\frac{\partial w}{\partial x}\right)^{2} d x \\
& -\frac{B_{11}}{L}\left[\frac{\partial w(L, t)}{\partial x}-\frac{\partial w(0, t)}{\partial x}\right] \\
& +\frac{E_{11}}{L}\left[u_{1}(L, t)-u_{1}(0, t)\right]-\left(N^{T}-N^{r}\right), \\
C_{2}= & \frac{1}{A_{11}}\left[E_{11} u_{1}(0, t)-B_{11} \frac{\partial w(0, t)}{\partial x}\right] .
\end{aligned}
$$

To this end, we can obtain the following axial force $N$ in terms of displacements:

$$
N=b\left(A_{11} A(t)-N^{T}+N^{r}\right)
$$

where

$$
\begin{aligned}
A(t)= & \frac{1}{2 L} \int_{0}^{L}\left(\frac{\partial w}{\partial x}\right)^{2} d x \\
& +\frac{E_{11}}{L A_{11}}\left(u_{1}(L, t)-u_{1}(0, t)\right) \\
& -\frac{B_{11}}{L A_{11}}\left(\frac{\partial w(L, t)}{\partial x}-\frac{\partial w(0, t)}{\partial x}\right) .
\end{aligned}
$$

Finally, by substituting (18) and (30) into the second and third equations of (26), the nonlinear equations of motion for SMA hybrid composite beam in terms of displacements can be written as

$$
\begin{gathered}
m_{1} \ddot{w}+m_{5} \frac{\partial \ddot{u}_{1}}{\partial x}-\left(\frac{B_{11}^{2}}{A_{11}}-D_{11}\right) \frac{\partial^{4} w}{\partial x^{4}} \\
-\left(F_{11}-\frac{B_{11} E_{11}}{A_{11}}\right) \frac{\partial^{3} u_{1}}{\partial x^{3}} \\
-\left(A_{11} A(t)-N^{T}+N^{r}\right) \frac{\partial^{2} w}{\partial x^{2}}=q, \\
m_{6} \ddot{u}_{1}-\left(H_{11}-\frac{E_{11}^{2}}{A_{11}}\right) \ddot{u}_{1}+A_{55} u_{1} \\
-\left(\frac{B_{11} E_{11}}{A_{11}}-F_{11}\right) \frac{\partial^{3} w}{\partial x^{3}}=0 .
\end{gathered}
$$

For a symmetric laminate, the stiffness coefficients $B_{11}=$ $E_{11}=0$. The equations of motion reduce to

$$
\begin{aligned}
& m_{1} \ddot{w}+m_{5} \frac{\partial \ddot{u}_{1}}{\partial x}+D_{11} \frac{\partial^{4} w}{\partial x^{4}}-F_{11} \frac{\partial^{3} u_{1}}{\partial x^{3}} \\
&-\left(\frac{A_{11}}{2 L} \int_{0}^{L}\left(\frac{\partial w}{\partial x}\right)^{2} d x-N^{T}+N^{r}\right) \frac{\partial^{2} w}{\partial x^{2}}=q, \\
& m_{6} \ddot{u}_{1}-H_{11} \frac{\partial^{2} u_{1}}{\partial x^{2}}+A_{55} u_{1}+F_{11} \frac{\partial^{3} w}{\partial x^{3}}=0 .
\end{aligned}
$$

The boundary conditions of a simply supported beam can be given as

$$
w=M=M_{s}=0, \quad \text { at } x=0, L .
$$

It can be proved that the simply supported boundary conditions also have the following form:

$$
\frac{\partial^{2} w}{\partial x^{2}}=\frac{\partial u_{1}}{\partial x}=0, \quad \text { at } x=0, L
$$


The Galerkin procedure is employed here to find the approximate solution of the nonlinear equations of motion (33). For simply supported beam the following form of displacements is assumed:

$$
\begin{gathered}
w(x, t)=A(t) \sin \frac{\pi x}{L}, \\
u_{1}(x, t)=B(t) \cos \frac{\pi x}{L} .
\end{gathered}
$$

Substitution of (36) into (33) and applying the Galerkin procedure yield

$$
\begin{aligned}
\frac{d^{2} A}{d t^{2}}+\alpha_{1} \frac{d^{2} B}{d t^{2}}+\alpha_{2} A+\alpha_{3} B+\alpha_{4} A^{3} & =\alpha_{5} \cos \omega t, \\
\frac{d^{2} B}{d t^{2}}+\beta_{1} B+\beta_{2} A & =0,
\end{aligned}
$$

where

$$
\begin{aligned}
& \alpha_{1}=-\frac{\pi m_{5}}{L m_{1}} \\
& \alpha_{2}=\frac{1}{m_{1}}\left[\left(\frac{\pi}{L}\right)^{4} D_{11}+\left(\frac{\pi}{L}\right)^{2}\left(-N^{T}+N^{r}\right)\right],
\end{aligned}
$$

$$
\begin{aligned}
& \alpha_{3}=-\frac{F_{11}}{m_{1}}\left(\frac{\pi}{L}\right)^{3}, \\
& \alpha_{4}=\frac{A_{11}}{4 m_{1}}\left(\frac{\pi}{L}\right)^{4}, \\
& \alpha_{5}=\frac{4 q_{0}}{m_{1}}, \\
& \beta_{1}=\frac{1}{m_{6}}\left[\left(\frac{\pi}{L}\right)^{2} H_{11}+A_{55}\right], \\
& \beta_{2}=-\frac{F_{11}}{m_{6}}\left(\frac{\pi}{L}\right)^{3} .
\end{aligned}
$$

In order to obtain the approximate solutions of nonlinear vibration (note that free vibration equations can be obtained from (37) by setting nonconservative force terms $\alpha_{5}$ equal to zero), we use the harmonic balance method to solve (37).

The nonlinear natural frequency equation and the steadystate forced response equation are obtained, respectively, as

$$
\begin{aligned}
& B_{0}=\frac{\beta_{2}}{\omega_{n}^{2}-\beta_{1}} A_{0}, \\
& \frac{3}{4} \alpha_{4} \bar{A}^{3}+\left[\frac{\left(\alpha_{3}-\alpha_{1} \omega^{2}\right) \beta_{2}}{\omega^{2}-\beta_{1}^{2}}+\alpha_{2}-\omega^{2}\right] \bar{A}-\alpha_{5}=0, \\
& \bar{B}=\frac{\beta_{2}}{\omega^{2}-\beta_{1}} \bar{A},
\end{aligned}
$$

where $A_{0}, B_{0}$ and $\bar{A}, \bar{B}$ are the nonlinear free and forced vibration amplitudes, respectively, and $\omega_{n}$ and $\omega$ are the nonlinear fundamental frequency and excited frequency, respectively.

\section{Numerical Results and Discussions}

3.1. Model Validation. Gunda et al. [11] presented large amplitude free vibration analysis of laminated composite beam based on the concept of coupled displacement field (CDF). They obtained the nonlinear natural frequency by using Rayleigh-Ritz (R-R) method. Accuracy of the closedform expressions presented using R-R (CDF) method was evaluated using the finite element formulation. A graphiteepoxy laminated simply supported beam with six layers of uniform thickness and having a length of $0.25 \mathrm{~m}$, a width of
$0.01 \mathrm{~m}$, and a height of $0.001 \mathrm{~m}$ is considered for establishing results [11]. The material properties considered are $E_{1}=$ $155 \mathrm{GPa}, E_{2}=12.1 \mathrm{GPa}, v_{12}=0.248, G_{12}=4.4 \mathrm{GPa}$, and $\rho=1570 \mathrm{~kg} / \mathrm{m}^{3}$.

Figure 1 presents the numerical results for the nonlinear natural frequency with the free vibration amplitude, as a function of the SMA fiber volume fraction $V_{s}$. For each stacking sequence as described in [11], the SMA fibers are arranged to orientate at $0^{\circ}$. The results show that higher nonlinear natural frequency can be achieved for the active composite beams as compared with exact results for passive one reported by Gunda et al. [11] $\left(V_{s}=0.0\right)$.

3.2. Parametric Analysis. Nonlinear free vibration and forced behavior of the composite beams with embedded SMA fibers are studied. The composite matrix material used in the 


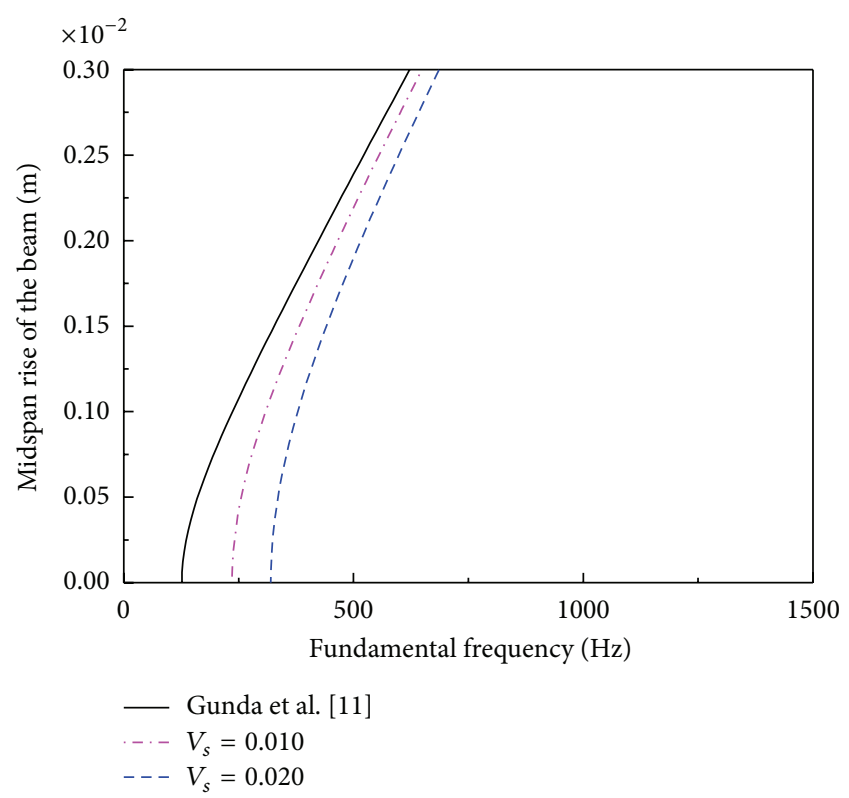

(a)

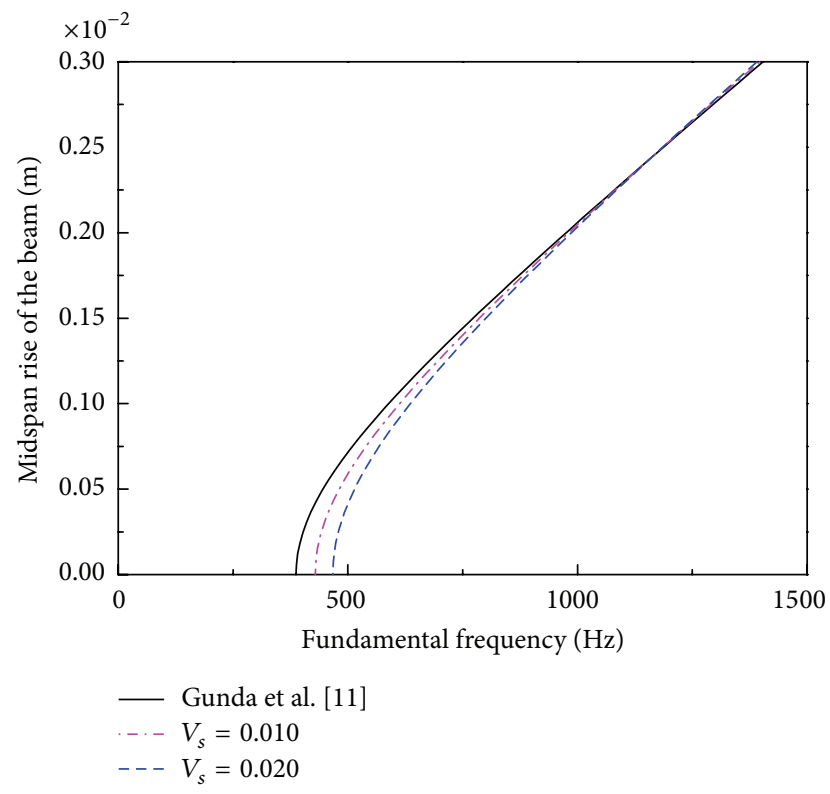

(c)

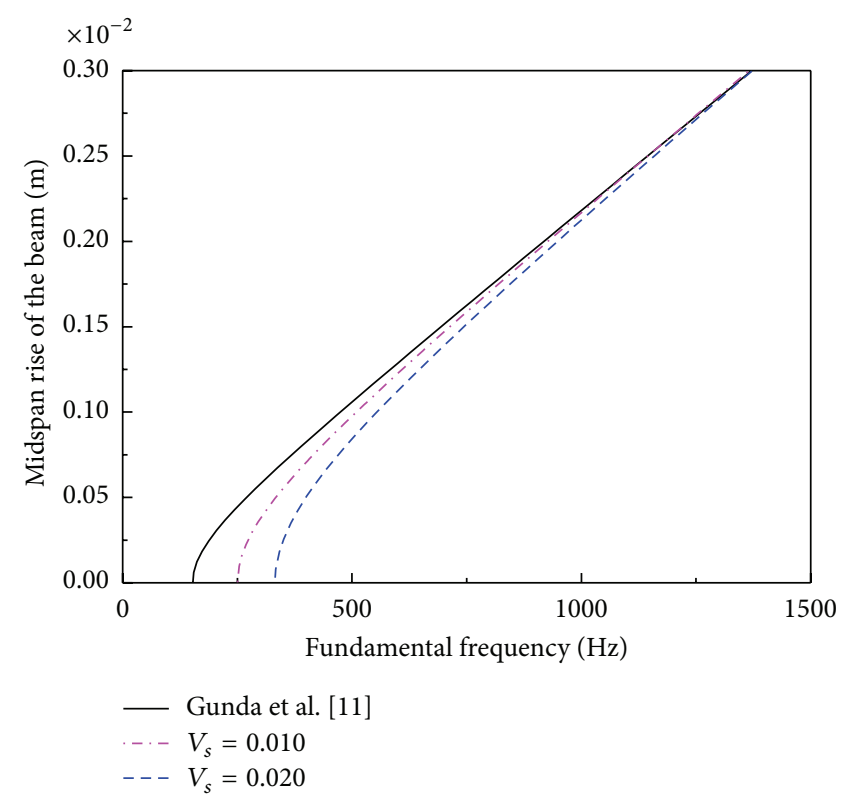

(b)

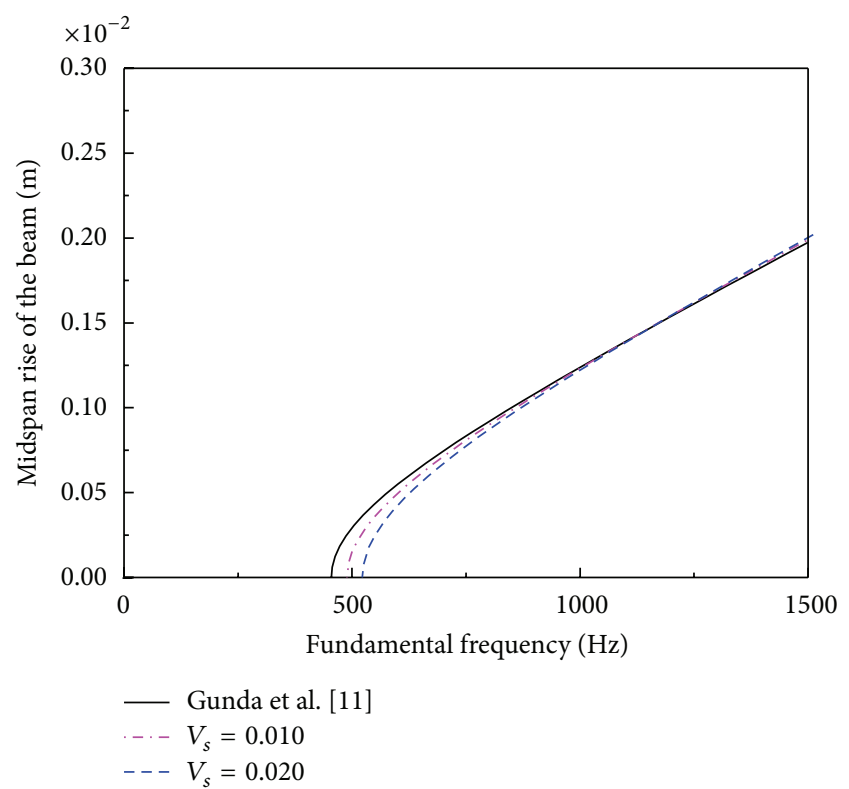

(d)

FIGURE 1: Large amplitude vibration behavior of laminated composite beams with symmetric layup orientations $\left(T=50^{\circ} \mathrm{C}, \varepsilon_{0}=0.03\right):(\mathrm{a})$ cross-ply; (b) $\left[90^{\circ} / 90^{\circ} / 0^{\circ}\right]_{s}$; (c) $\left[0^{\circ} / 90^{\circ} / 90^{\circ}\right]_{s}$; and (d) unidirectional.

numerical examples is glass/epoxy. Its properties are listed in Table 2 . The $\left[45 /-45 / 0_{\mathrm{SMA}} / 90\right]_{s}$ symmetrically laminated simply supported beam with eight layers of the same thickness and total thickness of $0.001 \mathrm{~m}$ is considered in this work. The material properties of SMA fiber are listed in Table 3.

The length and width of the beam are assumed to be $0.1 \mathrm{~m}$ and $0.01 \mathrm{~m}$, respectively.

The variation of the nonlinear natural frequency with the free vibration amplitude is presented in Figure 2. Composite
TABLE 2: The material parameters of glass/epoxy.

\begin{tabular}{lc}
\hline$E_{1 m}(\mathrm{GPa})$ & $25 \times 10^{-3}$ \\
$E_{2 m}(\mathrm{GPa})$ & $1 \times 10^{-3}$ \\
$G_{12 m}(\mathrm{GPa})$ & $0.5 \times 10^{-3}$ \\
$\rho\left(\mathrm{kg} / \mathrm{m}^{-3}\right)$ & 1856 \\
$v_{12 m}$ & 0.25 \\
$\alpha_{1 m}\left(1 /^{\circ} \mathrm{C}\right)$ & $0.2 \times 10^{-6}$ \\
$\alpha_{2 m}\left(1 /^{\circ} \mathrm{C}\right)$ & $16 \times 10^{-6}$ \\
\hline
\end{tabular}




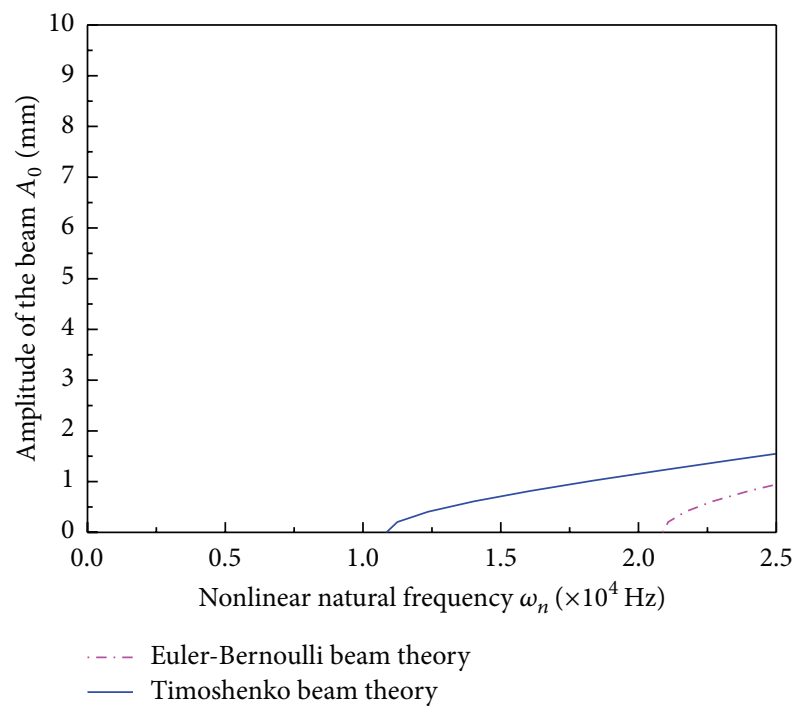

(a)

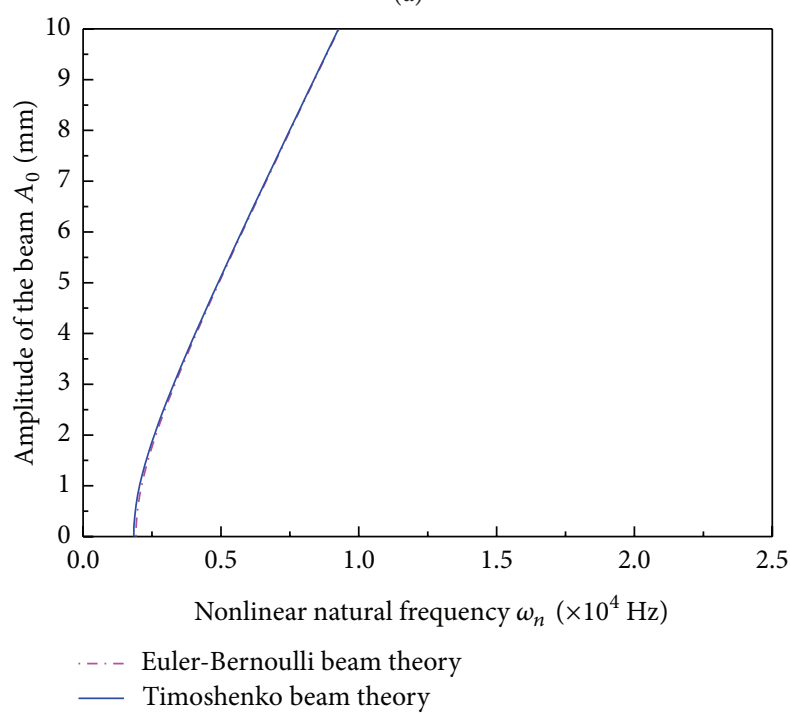

(c)

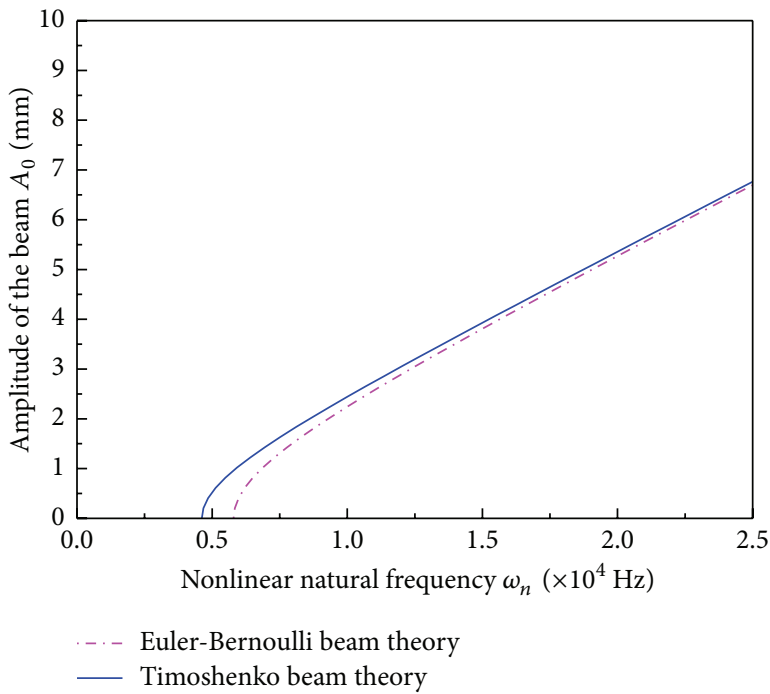

(b)

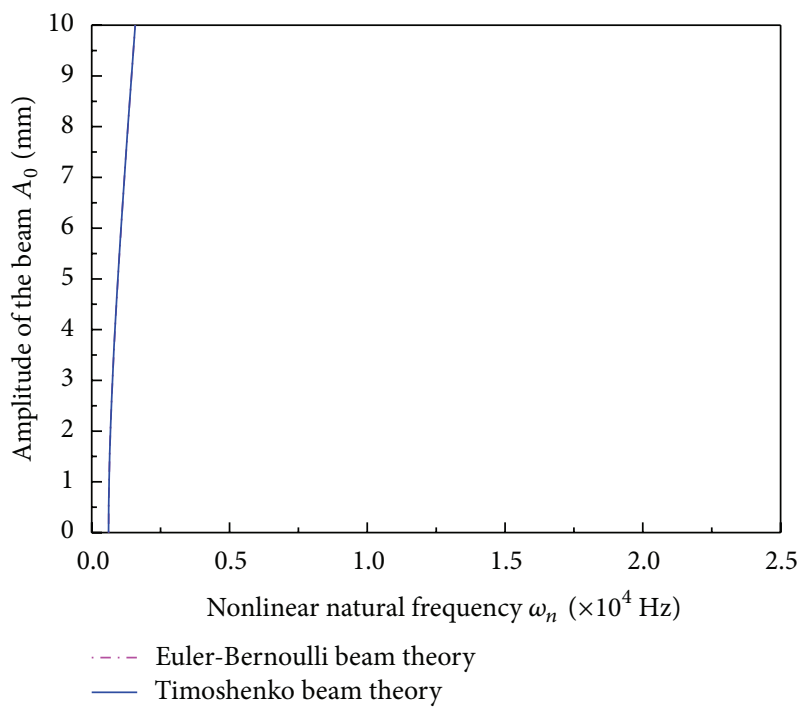

(d)

FIGURE 2: Variation of the nonlinear natural frequency with the free vibration amplitude $A_{0}\left(T=50^{\circ} \mathrm{C}, \varepsilon_{0}=0.03, V_{s}=0.005\right.$, and $\left.h=0.001 \mathrm{~m}\right)$ : (a) $L / h=5$; (b) $L / h=10$; (c) $L / h=20$; and (d) $L / h=50$.

TABLE 3: Material properties of SMA wires.

\begin{tabular}{lc}
\hline & SMA (nitinol) \\
\hline$E_{A} / \mathrm{MPa}$ & $67 \times 10^{3}$ \\
$E_{M} / \mathrm{MPa}$ & $26.3 \times 10^{3}$ \\
$\sigma_{s}^{\mathrm{cr}} / \mathrm{MPa}$ & 100 \\
$\sigma_{f}^{\mathrm{cr}} / \mathrm{MPa}$ & 170 \\
$\varepsilon_{L}$ & 0.067 \\
$\Theta /\left(\mathrm{MPa} /{ }^{\circ} \mathrm{C}\right)$ & 0.55 \\
$M_{f} /{ }^{\circ} \mathrm{C}$ & 9 \\
$M_{s} /{ }^{\circ} \mathrm{C}$ & 18.4 \\
$A_{s} /{ }^{\circ} \mathrm{C}$ & 34.5 \\
$A_{f} /{ }^{\circ} \mathrm{C}$ & 49 \\
$C_{M} /\left(\mathrm{MPa} /{ }^{\circ} \mathrm{C}\right)$ & 8 \\
$C_{A} /\left(\mathrm{MPa} /{ }^{\circ} \mathrm{C}\right)$ & 13.8 \\
$\rho /\left(\mathrm{kg} / \mathrm{m}^{3}\right)$ & 6450 \\
\hline
\end{tabular}

beams with four different $L / h$ (i.e., $L / h=5,10,20$, and 50) are considered. As can be seen from the figures, $L / h$ is an important parameter in the analysis of vibration of the composite beams. It is also seen that the shear deformation effect can be neglected for $L / h$ of 50 .

Table 4 presents the nonlinear natural frequency for the composite beams having different $V_{s}$ using different beam theories. In the table, it can be noted that the nonlinear natural frequencies initially decrease for the composite beams with low value of $V_{s}$. This is due to the compressive force induced by the thermal expansion of the composite and SMA fibers. The nonlinear natural frequencies are then increased with increasing of $V_{s}$. It is evidenced that the compressive force induced by the thermal expansion of the composite could be overcome by a tensile force induced by the strain recovery of the prestrained SMA fibers with high value of $V_{s}$ at a temperature above $A_{f}$. The above-mentioned 


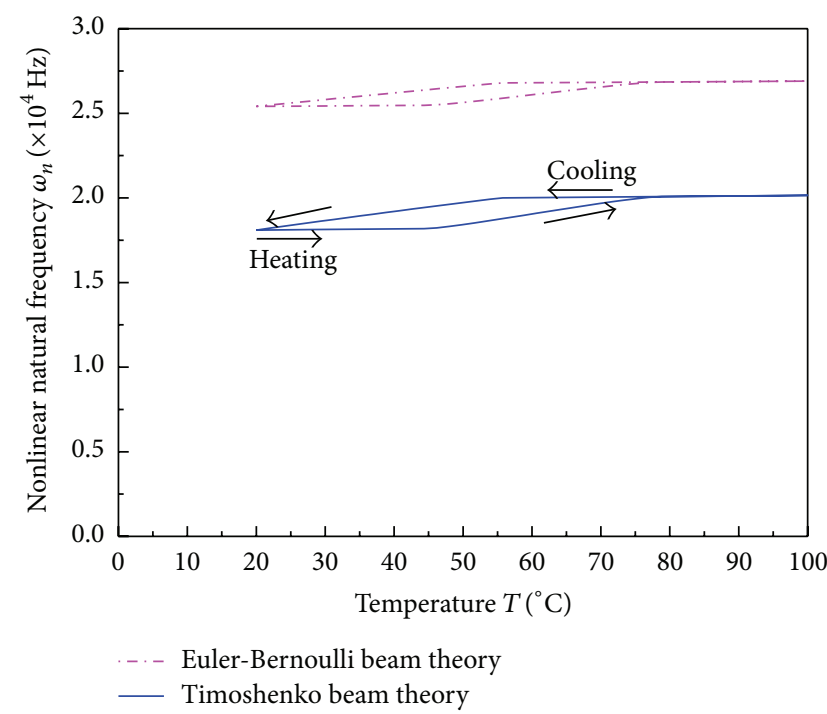

(a)

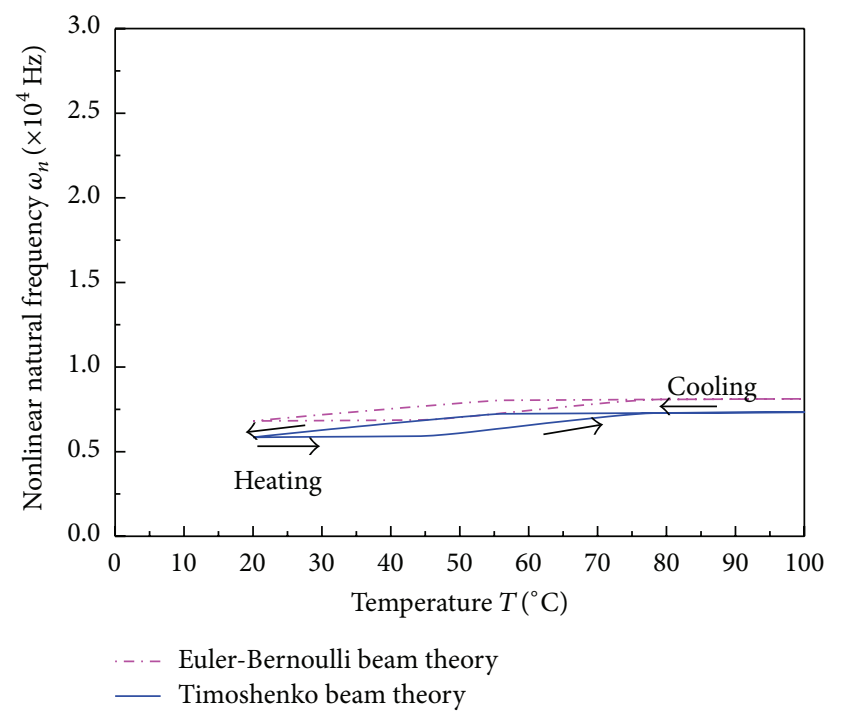

(b)

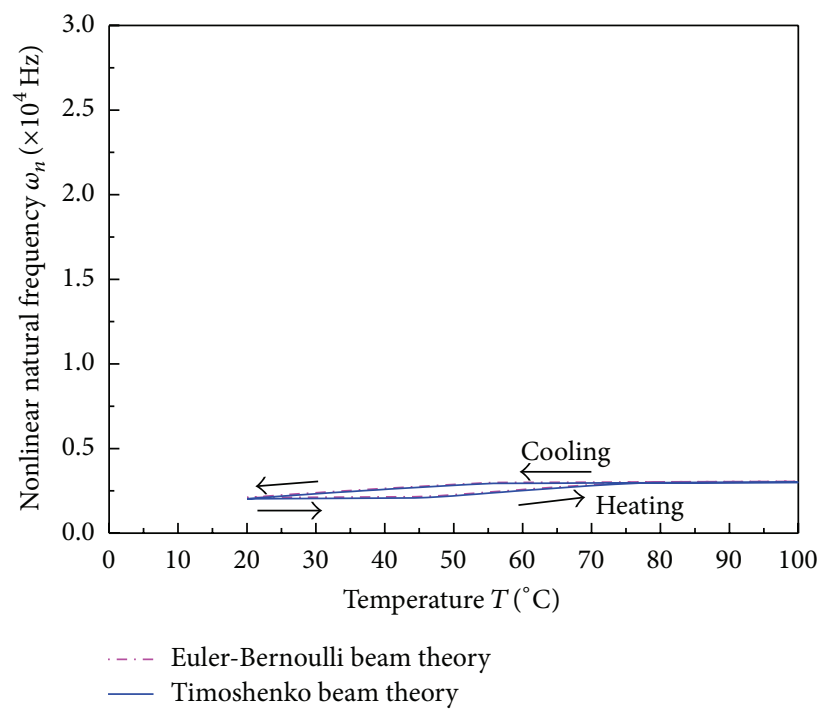

(c)

FIGURE 3: Variation of the nonlinear natural frequency with the actuation temperature of SMA fibers $\left(\varepsilon_{0}=0.03, V_{s}=0.005\right.$, and $\left.A_{0} / h=1\right)$ : (a) $L / h=5$; (b) $L / h=10$; and (c) $L / h=20$.

characteristics are more evident for higher value of $A_{0} / h$. It is also seen that, for the composite beams with high value of $A_{0} / h$, the effect of shear deformation is more significant.

Table 5 presents the nonlinear natural frequency for the composite beams having different $\varepsilon_{0}$ using different beam theories. As shown in the table, the initial strain of SMA fibers appears to have marginal effect on nonlinear natural frequencies.

Table 6 presents the nonlinear natural frequency for the composite beams having different $T$ using different beam theories. It can be observed that the actuation temperature of SMA fiber has much more influence for the low value of $A_{0} / h$ than for the high value of $A_{0} / h$.

The variation of the nonlinear natural frequency with the actuation temperature of SMA fibers for composite beams $\left(\varepsilon_{0}=0.03, V_{s}=0.005\right.$, and $\left.A_{0} / h=1\right)$ with three different $L / h$ (i.e., $L / h=5,10$, and 20) is presented in Figure 3. The phase transformation $M \rightarrow A$ is induced during heating, and the phase transformation $A \rightarrow M$ is induced during cooling. The curves of the nonlinear natural frequency versus temperature are typical hysteresis loops in a thermal cycle; the nonlinear natural frequency increases with the increase in temperature during heating, but decline with the decrease in temperature during cooling. Furthermore, it can be seen that the nonlinear natural frequency increases with a decrease in $L / h$ of the composite beam. In short composite beams, great differences exist between nonlinear natural frequencies evaluated using the Euler-Bernoulli's beam theory and Timoshenko's beam theory. However, these differences can be neglected in long composite beams. 


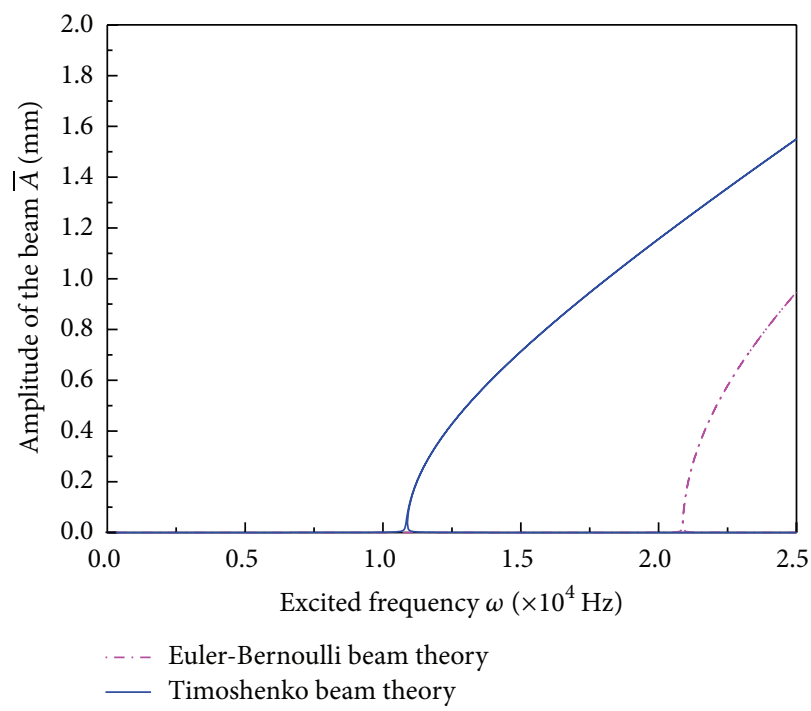

(a)

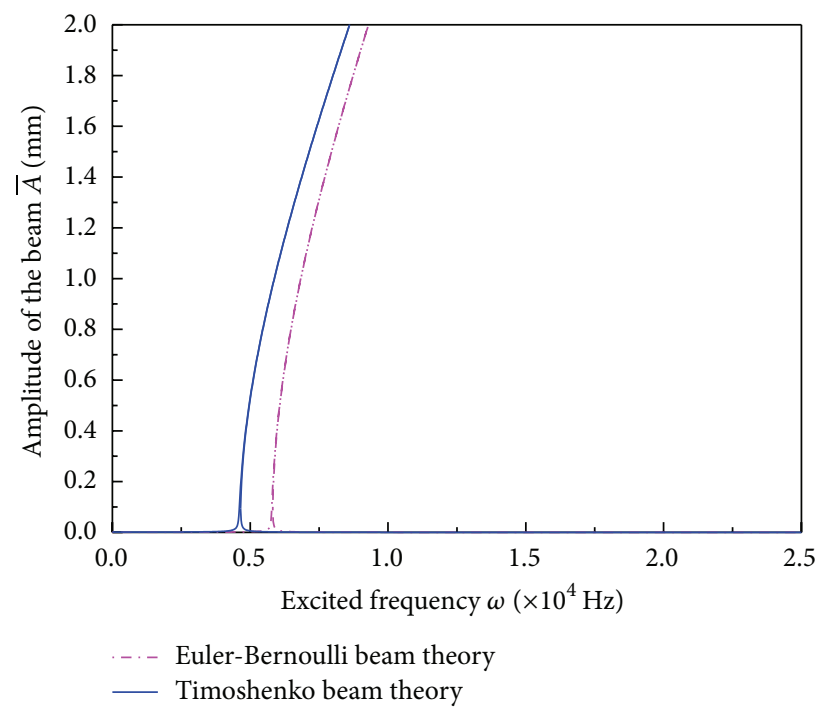

(b)

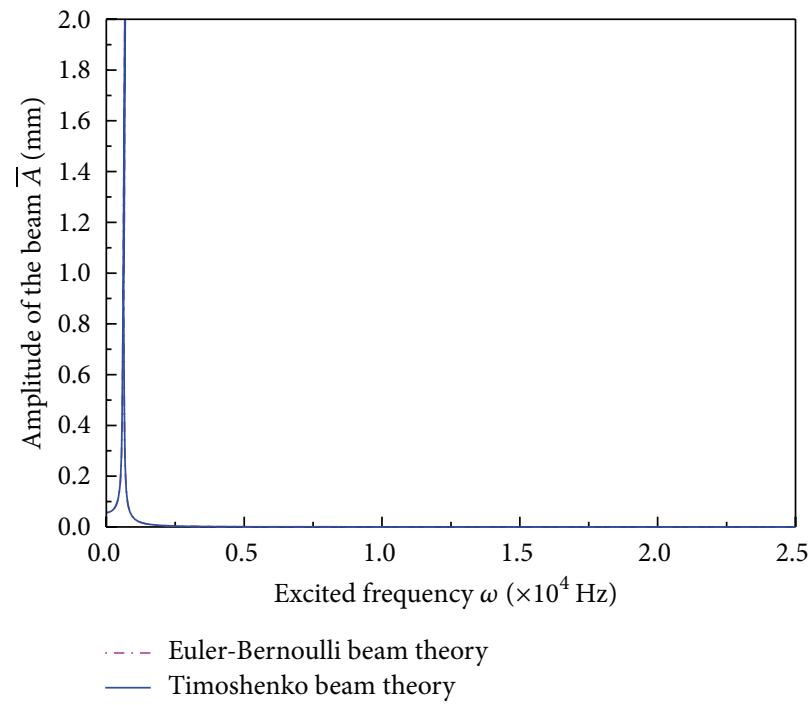

(c)

FIGURE 4: Frequency responses of the composite beams in the phase transformation state from martensite to austenite under the excitations $\left(T=50^{\circ} \mathrm{C}, \varepsilon_{0}=0.03, V_{s}=0.005\right.$, and $q_{0}=10 \mathrm{~N}$ ): (a) $L / h=5$; (b) $L / h=10$; and (c) $L / h=50$.

TABLE 4: The nonlinear natural frequency for different values of $V_{s}$ with various $A_{0} / h\left(L / h=6, T=60^{\circ} \mathrm{C}\right.$, and $\left.\varepsilon_{0}=0.03\right)$.

\begin{tabular}{lcccc}
\hline$A_{0} / h$ & Beam theory & $V_{s}=0.000$ & $V_{s}=0.005$ & $V_{s}=0.150$ \\
\hline \multirow{2}{*}{1} & Euler-Bernoulli & $2.0707 \times 10^{4}$ & $1.8512 \times 10^{4}$ & $3.9777 \times 10^{4}$ \\
& Timoshenko & $1.4572 \times 10^{4}$ & $1.4222 \times 10^{4}$ & $3.8129 \times 10^{4}$ \\
\hline \multirow{2}{*}{5} & Euler-Bernoulli & $6.4337 \times 10^{4}$ & $5.2779 \times 10^{4}$ & $6.1971 \times 10^{4}$ \\
& Timoshenko & $6.2632 \times 10^{4}$ & $5.1432 \times 10^{4}$ & $6.0927 \times 10^{4}$ \\
\hline \multirow{2}{*}{7} & Euler-Bernoulli & $8.8599 \times 10^{4}$ & $7.2309 \times 10^{4}$ & $7.8094 \times 10^{4}$ \\
& Timoshenko & $8.7369 \times 10^{4}$ & $7.1331 \times 10^{4}$ & $7.7268 \times 10^{4}$ \\
\hline
\end{tabular}

Amplitude $\bar{A}$ versus frequency responses of the composite beams with SMA fibers in the phase transformation state from martensite to austenite are shown, respectively, in Figure 4 under the excitations. In the figure, $L / h$ varying from 5 to 50 are considered to observe their effects on the steady-state responses. From the three figures it can be seen that deformation shear has significant effect on the shapes of the frequency-response curves for lower $L / h$. The results also show that the response curves bend more strongly towards the $\omega$-axis direction as $L / h$ decreases. 
TABLE 5: The nonlinear natural frequency for different values of $\varepsilon_{0}$ with various $A_{0} / h\left(L / h=6, T=60^{\circ} \mathrm{C}\right.$, and $\left.V_{s}=0.005\right)$.

\begin{tabular}{lcccc}
\hline$A_{0} / h$ & Beam theory & $\varepsilon_{0}=0.000$ & $\varepsilon_{0}=0.030$ & $\varepsilon_{0}=0.075$ \\
\hline \multirow{2}{*}{1} & Euler-Bernoulli & $1.8463 \times 10^{4}$ & $1.8512 \times 10^{4}$ & $1.8564 \times 10^{4}$ \\
& Timoshenko & $1.4159 \times 10^{4}$ & $1.4222 \times 10^{4}$ & $1.4290 \times 10^{4}$ \\
\hline \multirow{2}{*}{5} & Euler-Bernoulli & $5.2761 \times 10^{4}$ & $5.2779 \times 10^{4}$ & $5.2798 \times 10^{4}$ \\
& Timoshenko & $5.1413 \times 10^{4}$ & $5.1432 \times 10^{4}$ & $5.1451 \times 10^{4}$ \\
\hline \multirow{2}{*}{7} & Euler-Bernoulli & $7.2295 \times 10^{4}$ & $7.2309 \times 10^{4}$ & $7.2323 \times 10^{4}$ \\
& Timoshenko & $7.1317 \times 10^{4}$ & $7.1331 \times 10^{4}$ & $7.1346 \times 10^{4}$ \\
\hline
\end{tabular}

TABLE 6: The nonlinear natural frequency for different values of $T$ with various $A_{0} / h\left(L / h=6, \varepsilon_{0}=0.03\right.$, and $\left.V_{s}=0.005\right)$.

\begin{tabular}{lcccc}
\hline$A_{0} / h$ & Beam theory & $T=20^{\circ} \mathrm{C}$ & $T=60^{\circ} \mathrm{C}$ & $T=120^{\circ} \mathrm{C}$ \\
\hline \multirow{2}{*}{1} & Euler-Bernoulli & $1.7838 \times 10^{4}$ & $1.8512 \times 10^{4}$ & $1.9347 \times 10^{4}$ \\
& Timoshenko & $1.3332 \times 10^{4}$ & $1.4222 \times 10^{4}$ & $1.5295 \times 10^{4}$ \\
\hline \multirow{2}{*}{5} & Euler-Bernoulli & $5.2551 \times 10^{4}$ & $5.2779 \times 10^{4}$ & $5.3073 \times 10^{4}$ \\
& Timoshenko & $5.1197 \times 10^{4}$ & $5.1432 \times 10^{4}$ & $7.1733 \times 10^{4}$ \\
\hline \multirow{2}{*}{7} & Euler-Bernoulli & $7.2145 \times 10^{4}$ & $7.2309 \times 10^{4}$ & $7.2520 \times 10^{4}$ \\
& Timoshenko & $7.1165 \times 10^{4}$ & $7.1331 \times 10^{4}$ & $7.1545 \times 10^{4}$ \\
\hline
\end{tabular}

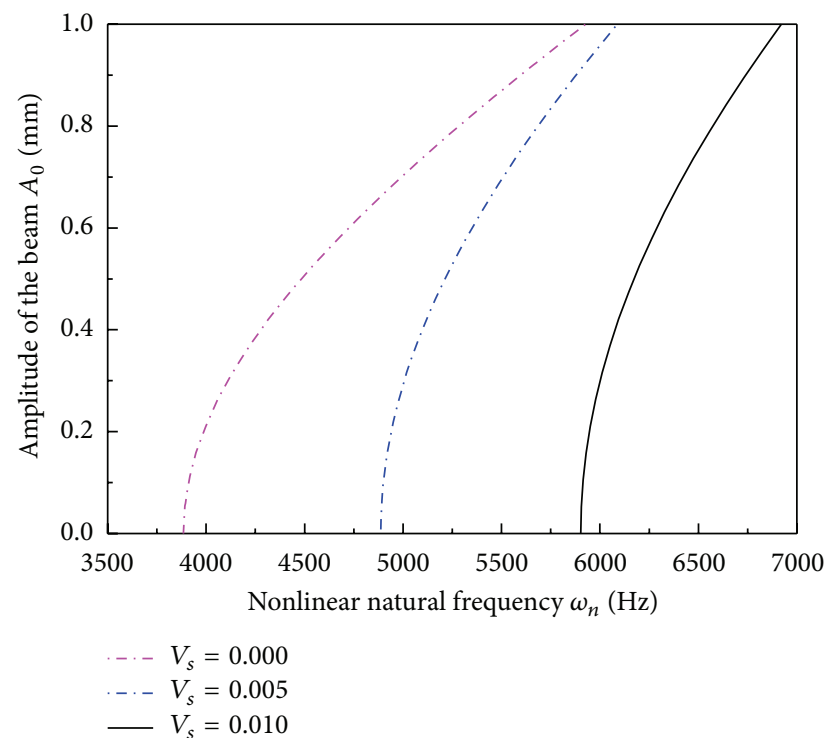

FIGURE 5: Variation of the nonlinear natural frequency with the free vibration amplitude $A_{0}$ for different $V_{s}\left(T=50^{\circ} \mathrm{C}, \varepsilon_{0}=0.005\right.$, and $L / h=10)$.

Figures 5 and 6 present the variation of the nonlinear natural frequency with the free vibration amplitude for different $V_{s}$. The results show that the effect of SMA fiber volume fraction is important.

Figures 7 and 8 present the variation of the nonlinear natural frequency with the free vibration amplitude for different $T$. The results show that the nonlinear natural frequency increases with the increase of the actuation temperature of SMA fibers.

Figures 9 and 10 present the variation of the nonlinear natural frequency with the free vibration amplitude for different $\varepsilon_{0}$. The results show that the initial strain of SMA

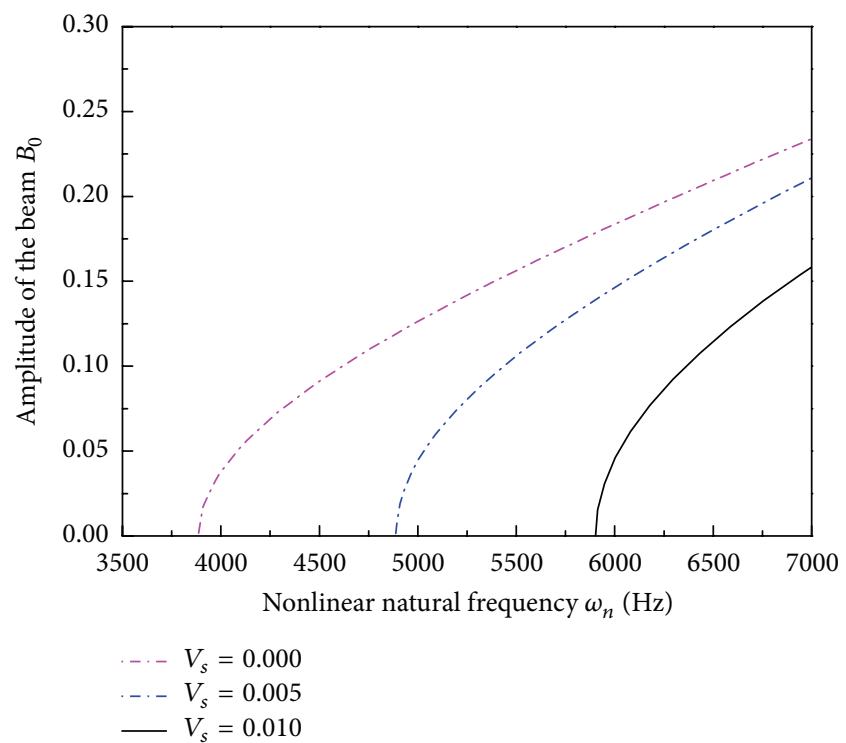

FIGURE 6: Variation of the nonlinear natural frequency with the free vibration amplitude $B_{0}$ for different $V_{s}\left(T=50^{\circ} \mathrm{C}, \varepsilon_{0}=0.005\right.$, and $L / h=10)$.

fibers appears to have marginal effect on the nonlinear natural frequency.

Figure 11 presents variation of the nonlinear natural frequency with the actuation temperature of SMA fibers for the composite beams with different $V_{s}$. As shown in Figure 11, the nonlinear natural frequency of the composite beam without SMA fibers $\left(V_{s}=0\right)$ is seen to decrease linearly with the increase of temperature. This is because there is not recovery stress of the SMA fiber in this case, as a result of the stiffness softening; therefore, the nonlinear natural frequency is reduced. However, it is seen from Figure 11 that SMA fiber embeddings result in significant increase of the nonlinear 


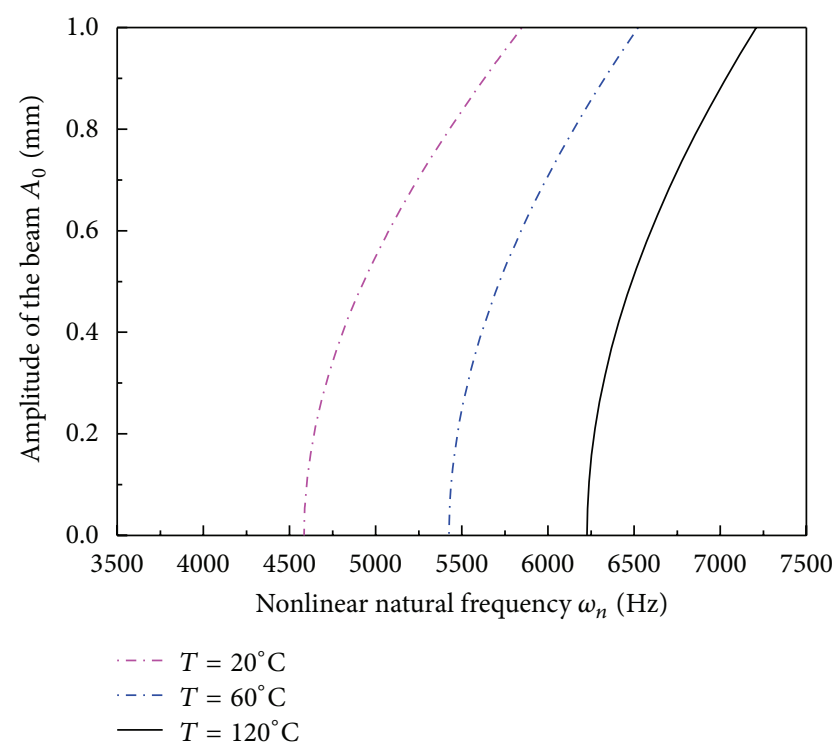

FIGURE 7: Variation of the nonlinear natural frequency with the free vibration amplitude $A_{0}$ for different $T\left(V_{s}=0.005, \varepsilon_{0}=0.01\right.$, and $L / h=10)$.

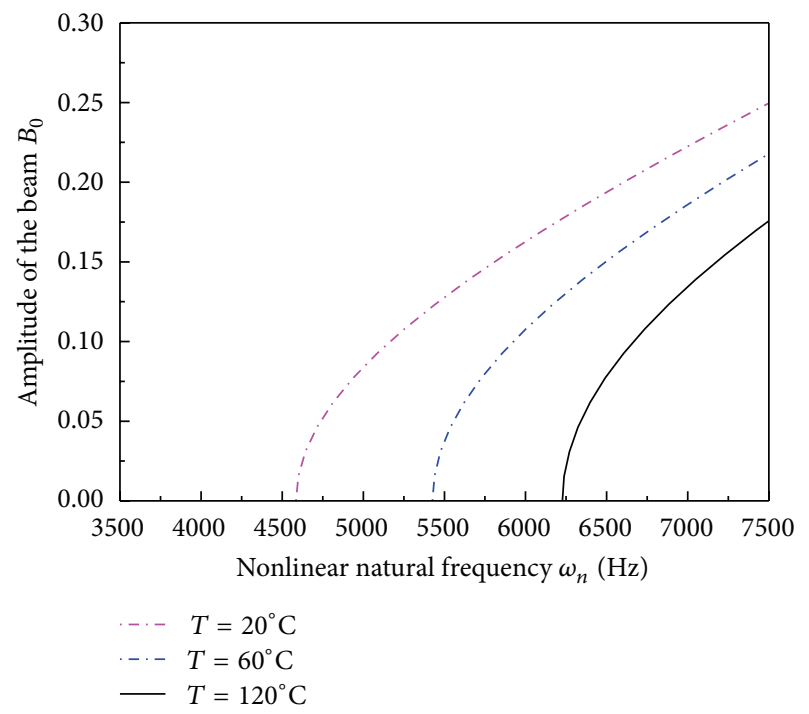

FIGURE 8: Variation of the nonlinear natural frequency with the free vibration amplitude $B_{0}$ for different $T\left(V_{s}=0.005, \varepsilon_{0}=0.01\right.$, and $L / h=10)$.

natural frequency compared with the result of the composite beams without SMA.

Figure 12 presents variation of the nonlinear natural frequency with the actuation temperature of SMA fibers for the composite beams with different $\varepsilon_{0}$. The results show that there is an obvious change in the shapes of nonlinear natural frequency versus temperature curves as the initial strain of SMA wire is increased.

Figure 13 presents variation of the nonlinear natural frequency with the actuation temperature of SMA fibers for the composite beams with different $A_{0}$. The increase of free vibration amplitude is accompanied by the shift of

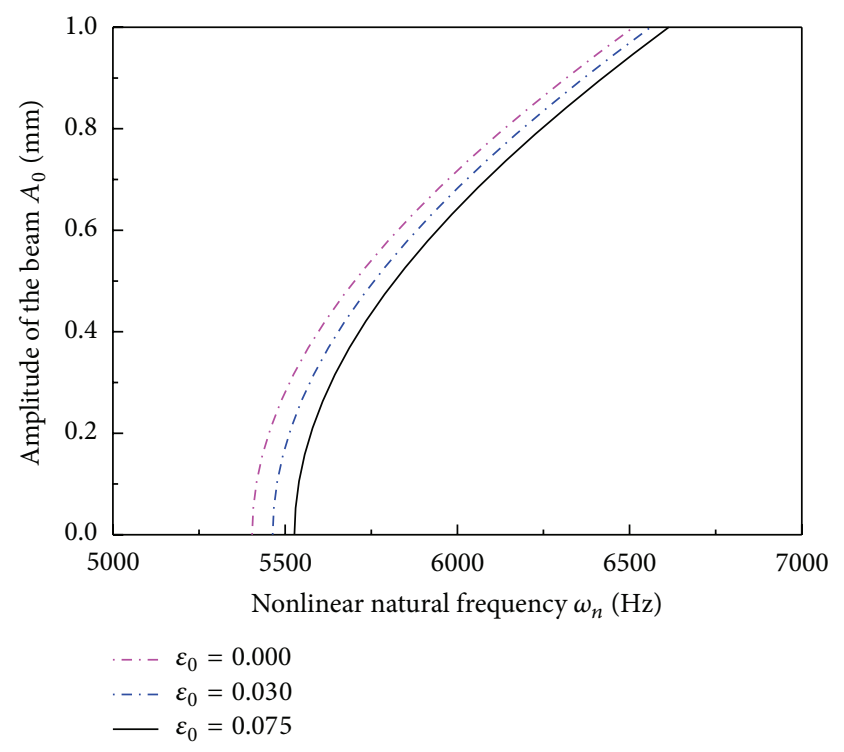

FIGURE 9: Variation of the nonlinear natural frequency with the free vibration amplitude $A_{0}$ for different $\varepsilon_{0}\left(V_{s}=0.005, T=60^{\circ} \mathrm{C}\right.$, and $L / h=10)$.

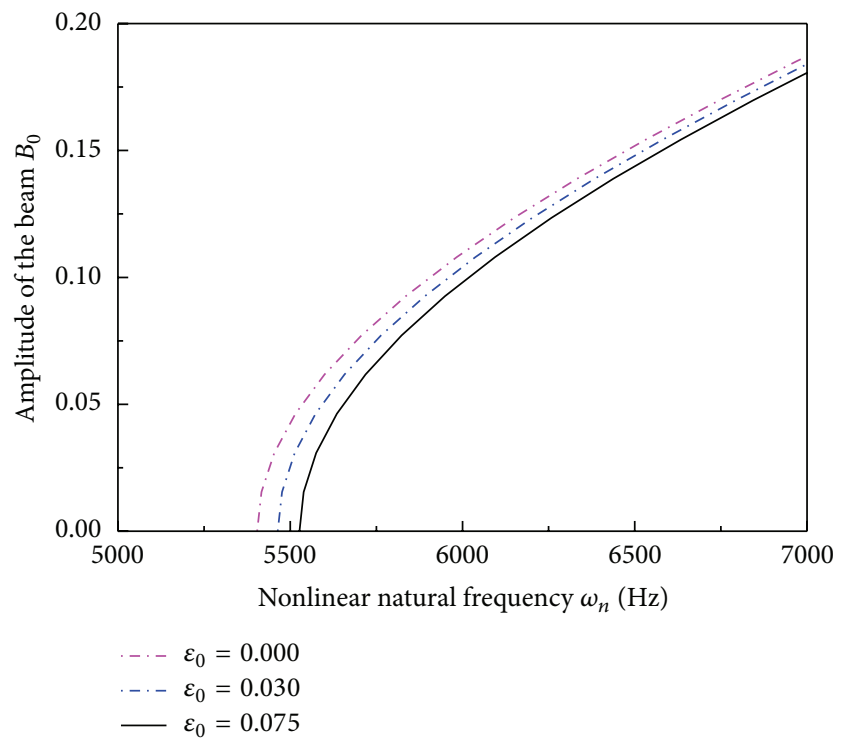

FIGURE 10: Variation of the nonlinear natural frequency with the free vibration amplitude $B_{0}$ for different $\varepsilon_{0}\left(V_{s}=0.005, T=60^{\circ} \mathrm{C}\right.$, and $L / h=10)$.

these hysteresis loops of nonlinear natural frequency versus temperature towards higher nonlinear natural frequency. It seems that the hysteresis effect is more significant for linear vibration beam $\left(A_{0}=0\right)$, in comparison with nonlinear vibration beams $\left(A_{0} \neq 0\right)$.

Figures 14 and 15 present the variation of amplitudes $\bar{A}$ and $\bar{B}$ with excited frequency, respectively. Also the effect of the volume fraction of SMA fibers is shown in these figures. The results show that the increase of $V_{s}$ leads to the 


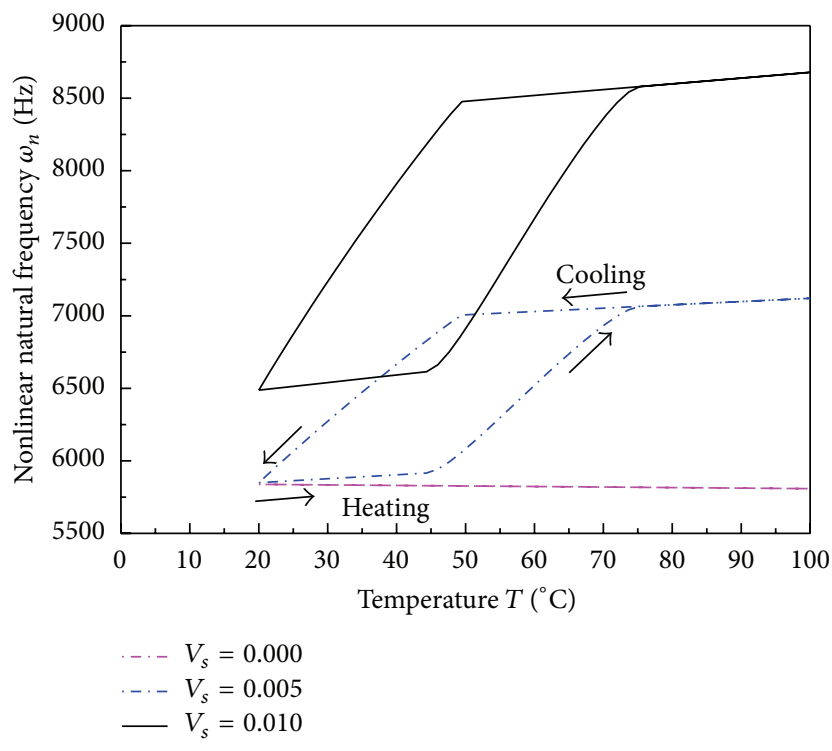

FIGURE 11: Variation of the nonlinear natural frequency with the actuation temperature for different $V_{s}\left(\varepsilon_{0}=0.03, A_{0} / h=1\right.$, and $L / h=10)$.

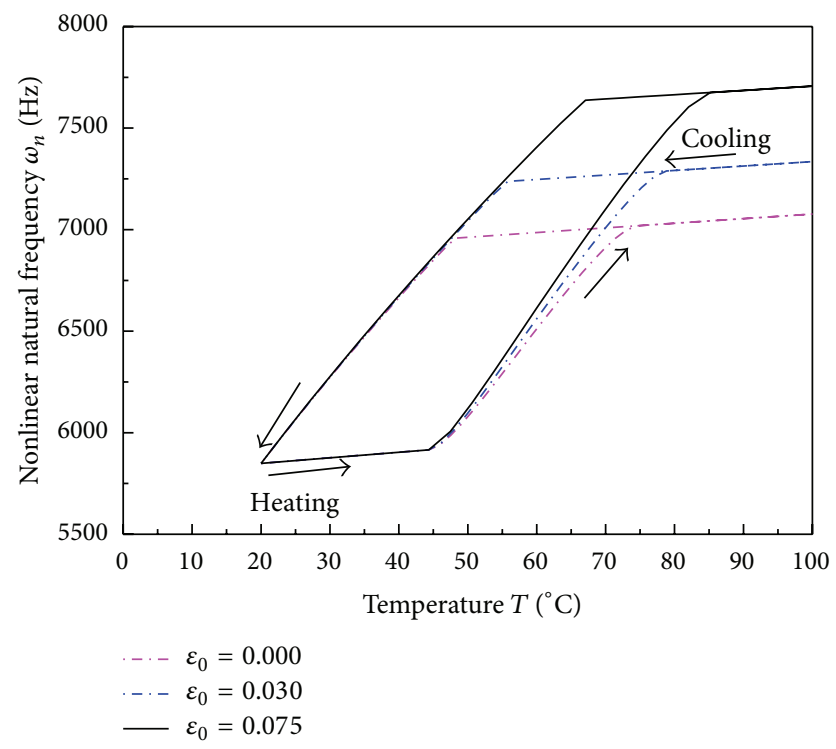

Figure 12: Variation of the nonlinear natural frequency with the actuation temperature for different $\varepsilon_{0}\left(V_{s}=0.005, A_{0} / h=1\right.$, and $L / h=10)$.

shift of steady-state responses curves towards higher excited frequency.

Figures 16 and 17 present the variation of amplitudes $\bar{A}$ and $\bar{B}$ with excited frequency, respectively. The effect of $\varepsilon_{0}$ is also considered. It can be seen that the increase of $\varepsilon_{0}$ leads to the shift of steady-state responses curves towards higher excited frequency.

Figures 18 and 19 present the variation of amplitudes $\bar{A}$ and $\bar{B}$ with excited frequency, respectively, for different $T$. As

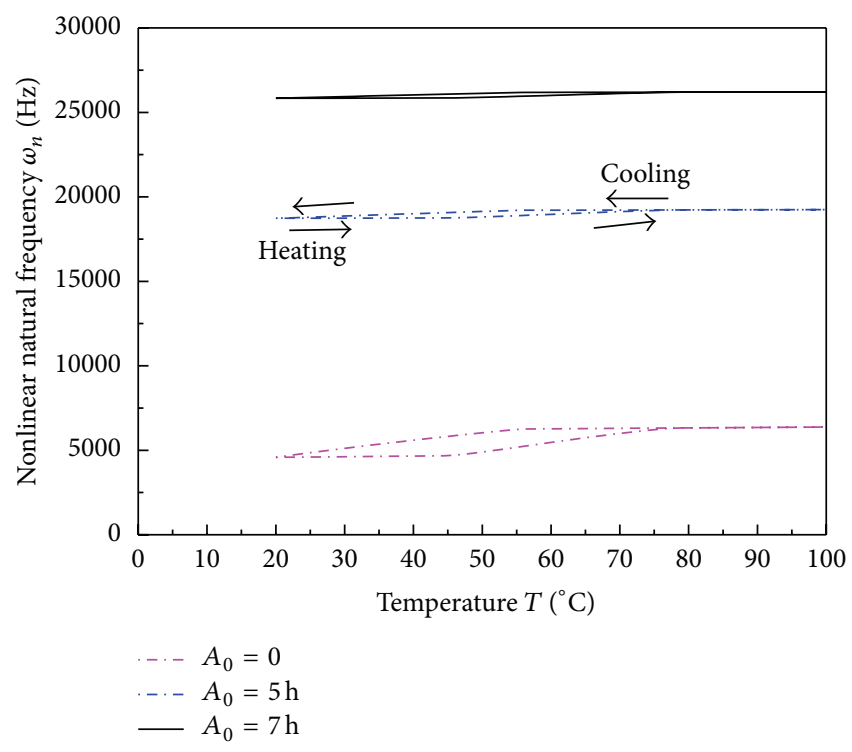

FIGURE 13: Variation of the nonlinear natural frequency with the actuation temperature for different $A_{0}\left(\varepsilon_{0}=0.03, V_{s}=0.005\right.$, and $L / h=10)$.

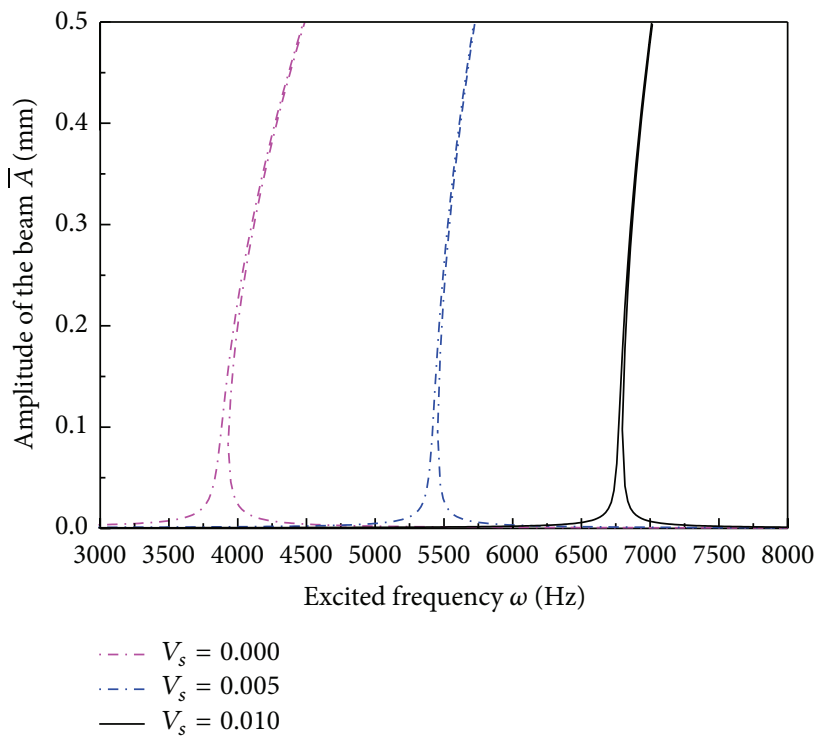

Figure 14: Amplitude $\bar{A}$ versus frequency responses of the composite beams in the phase transformation state from martensite to austenite under the excitations $\left(T=60^{\circ} \mathrm{C}, \varepsilon_{0}=0.008, q_{0}=10 \mathrm{~N}\right.$, and $L / h=10$ ).

can be clearly seen in the figure, the steady-state responses curves shift towards higher excited frequency as $T$ increases.

\section{Conclusions}

Large amplitude free and forced vibration of the composite beams embedded with SMA fibers are presented. The presented model was used to predict the nonlinear natural frequencies and steady-state forced responses. Emphasis is placed on the study of the effects of shear deformation and 


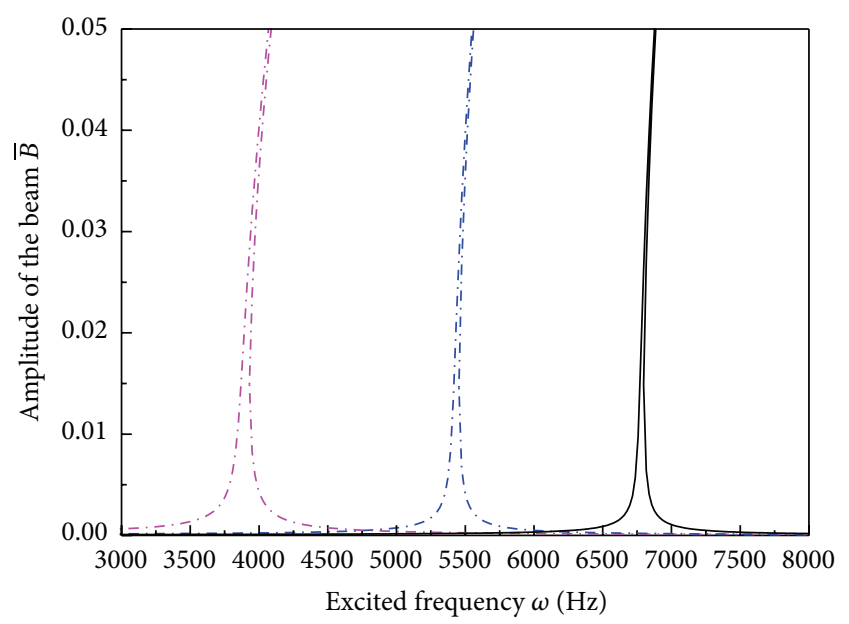

$$
\begin{aligned}
--V_{s} & =0.000 \\
--V_{s} & =0.005 \\
-V_{s} & =0.010
\end{aligned}
$$

FIgURE 15: Amplitude $\bar{B}$ versus frequency responses of the composite beams in the phase transformation state from martensite to austenite under the excitations for different $V_{s}\left(T=60^{\circ} \mathrm{C}, \varepsilon_{0}=0.008\right.$, $q_{0}=10 \mathrm{~N}$, and $\left.L / h=10\right)$.

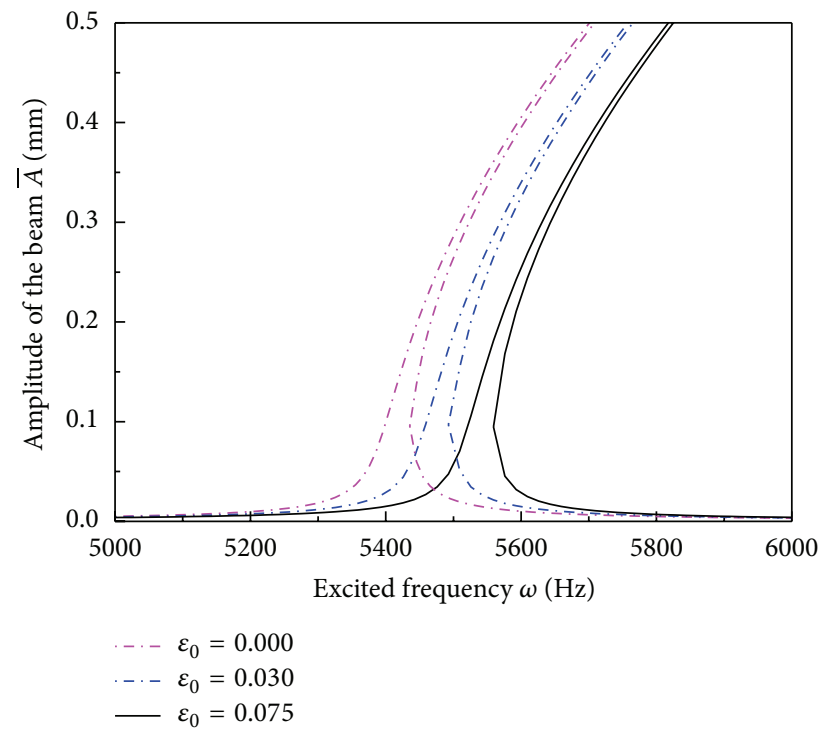

Figure 16: Amplitude $\bar{A}$ versus frequency responses of the composite beams in the phase transformation state from martensite to austenite under the excitations for different $\varepsilon_{0}\left(T=60^{\circ} \mathrm{C}, V_{s}=0.005\right.$, $q_{0}=10 \mathrm{~N}$, and $\left.L / h=10\right)$.

SMA activation on the nonlinear dynamical behavior. The effect of shear deformation is modeled based on the firstorder shear deformation beam theory. The recovery stress in the SMA fibers is found by employing thermomechanical constitutive equation of SMA proposed by Brinson. The von Kármán type nonlinear strain-displacement equation and Hamilton's principle are used to derive the equations of motion for the composite beams embedded with SMA fibers. Using an analytical method based on the Galerkin method,

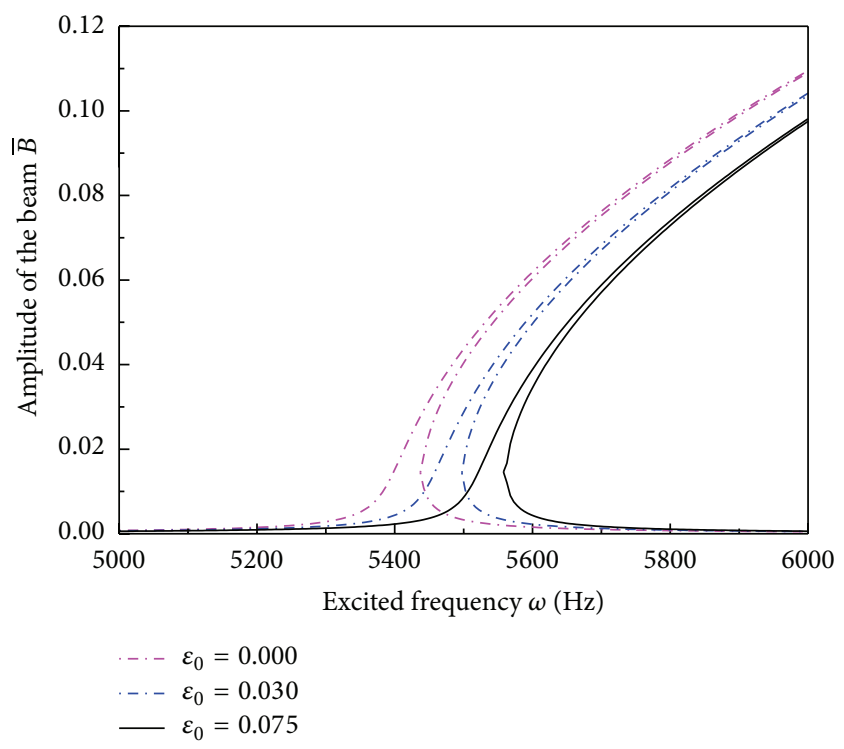

FIgURE 17: Amplitude $\bar{B}$ versus frequency responses of the composite beams in the phase transformation state from martensite to austenite under the excitations for different $\varepsilon_{0}\left(T=60^{\circ} \mathrm{C}, V_{s}=0.005\right.$, $q_{0}=10 \mathrm{~N}$, and $\left.L / h=10\right)$.

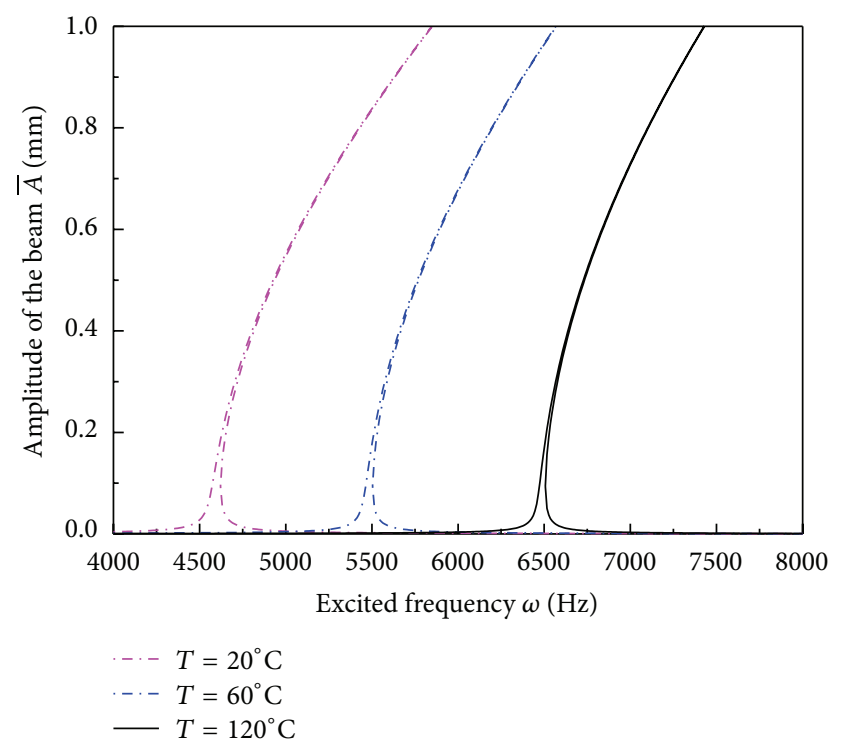

Figure 18: Amplitude $\bar{A}$ versus frequency responses of the composite beams in the phase transformation state from Martensite to Austenite under the excitations for different $T\left(\varepsilon_{0}=0.036, V_{s}=\right.$ $\left.0.005, q_{0}=10 \mathrm{~N}, L / h=10\right)$.

the nonlinear governing equations of motion are solved. The closed-form solution is obtained for nonlinear free vibration and forced vibration analysis of the composite beams with SMA fibers. From the present analysis and the numerical results, the following main conclusions can be obtained:

(1) Using the first-order shear deformation theory, the nonlinear natural frequency is found to be much lower than its value predicted by the classical beam 


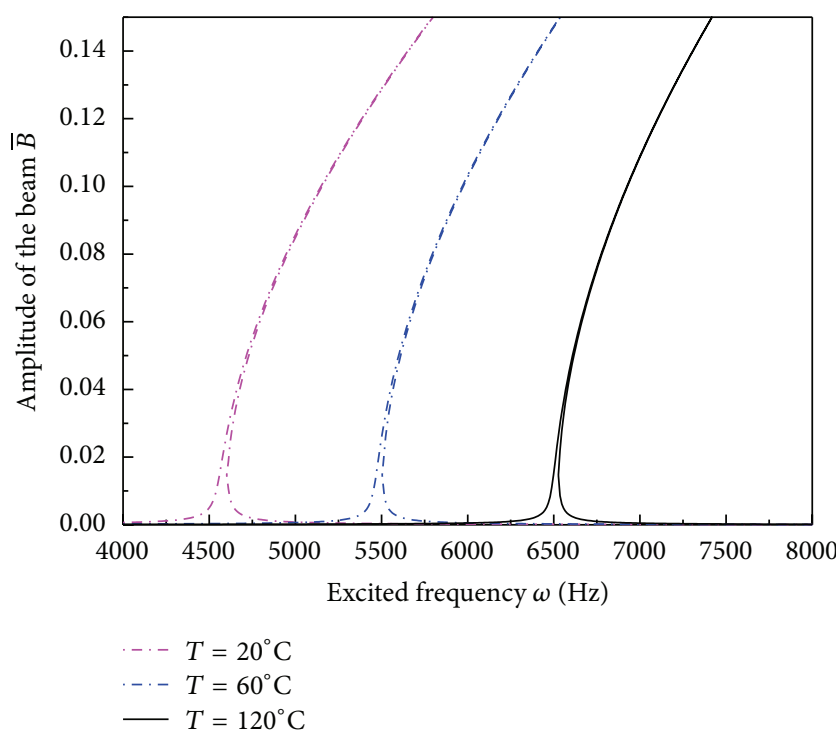

Figure 19: Amplitude $\bar{B}$ versus frequency responses of the composite beams in the phase transformation state from martensite to austenite under the excitations for different $T\left(\varepsilon_{0}=0.036, V_{s}=\right.$ $0.005, q_{0}=10 \mathrm{~N}$, and $L / h=10$ ).

theory. Thus, the nonlinear natural frequency predicted by the classical beam theory is overestimated. However, the amplitude of forced response is underestimated based on the classical beam theory. The effect of the shear deformation may be neglected if the value of $L / h$ is about 50 .

(2) SMA fibers' activation can significantly increase the nonlinear natural frequency through SMA phase transformation.

(3) The volume fraction and the actuation temperature of SMA fibers affect the actuation performance of SMA significantly. There is an obvious increase in the nonlinear natural frequency as the SMA fibers' fraction or actuation temperature is increased. In comparison with these two parameters, the initial strain of SMA fibers appears to have marginal effect on the nonlinear vibration behavior of the composite beams.

\section{Competing Interests}

The authors declare that they have no competing interests.

\section{Acknowledgments}

This research is funded by the National Natural Science Foundation of China (Grant no. 11272190), Shandong Provincial Natural Science Foundation of China (Grant no. ZR2011EEM031), and Graduate Innovation Project of Shandong University of Science and Technology of China (Grant no. YC150325).

\section{References}

[1] J. Zou, The constitutive relation of shape memory alloy and the analysis by the finite element method of shape memory alloy reinforced composite laminated plates [Ph.D. thesis], Huazhong University of Science and Technology, WuHan, China, 1999.

[2] S.-Y. Kuo, L.-C. Shiau, and C.-H. Lai, "Flutter of buckled shape memory alloy reinforced laminates," Smart Materials and Structures, vol. 21, no. 3, Article ID 035020, 2012.

[3] J.-S. Park, J.-H. Kim, and S.-H. Moon, “Thermal post-buckling and flutter characteristics of composite plates embedded with shape memory alloy fibers," Composites Part B: Engineering, vol. 36, no. 8, pp. 627-636, 2005.

[4] J.-S. Park, J.-H. Kim, and S.-H. Moon, "Vibration of thermally post-buckled composite plates embedded with shape memory alloy fibers," Composite Structures, vol. 63, no. 2, pp. 179-188, 2004.

[5] S.-R. Li, W.-S. Yu, and R. C. Batra, "Free vibration of thermally pre/post-buckled circular thin plates embedded with shape memory alloy fibers," Journal of Thermal Stresses, vol. 33, no. 2, pp. 79-96, 2010.

[6] L.-C. Shiau, S.-Y. Kuo, and S.-Y. Chang, "Free vibration of buckled SMA reinforced composite laminates," Composite Structures, vol. 93, no. 11, pp. 2678-2684, 2011.

[7] Y. S. Ren and S. S. Sun, "Large amplitude flexural vibration of the orthotropic composite plate embedded with shape memory alloy fibers," Chinese Journal of Aeronautics, vol. 20, no. 5, pp. 415-424, 2007.

[8] H. Asadi, M. Bodaghi, M. Shakeri, and M. M. Aghdam, "An analytical approach for nonlinear vibration and thermal stability of shape memory alloy hybrid laminated composite beams," European Journal of Mechanics, A/Solids, vol. 42, pp. 454-468, 2013.

[9] H. Asadi, M. Bodaghi, M. Shakeri, and M. M. Aghdam, "Nonlinear dynamics of SMA-fiber-reinforced composite beams subjected to a primary/secondary-resonance excitation," Acta Mechanica, vol. 226, no. 2, pp. 437-455, 2015.

[10] S. A. Emam, "Analysis of shear-deformable composite beams in postbuckling," Composite Structures, vol. 94, no. 1, pp. 24-30, 2011.

[11] J. B. Gunda, R. K. Gupta, G. R. Janardhan, and G. V. Rao, "Large amplitude vibration analysis of composite beams: simple closed-form solutions," Composite Structures, vol. 93, no. 2, pp. 870-879, 2011.

[12] L. C. Brinson, "One-dimensional constitutive behavior of shape memory alloys: thermomechanical derivation with non-constant material functions and redefined martensite internal variable," Journal of Intelligent Material Systems and Structures, vol. 4, no. 2, pp. 229-242, 1993.

[13] Z. W. Zhong, R. R. Chen, C. Mei, and C. S. Pates III, "Buckling and postbuckling of shape memory alloy fiber-reinforced composite plates," in Proceedings of the 1994 International Mechanical Engineering Congress and Exposition, pp. 115-132, ASME, New York, NY, USA, November 1994. 


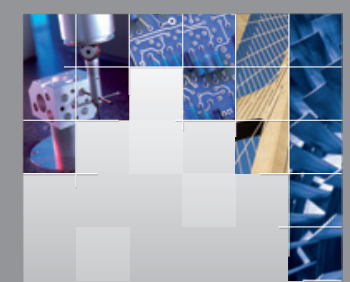

\section{Enfincering}
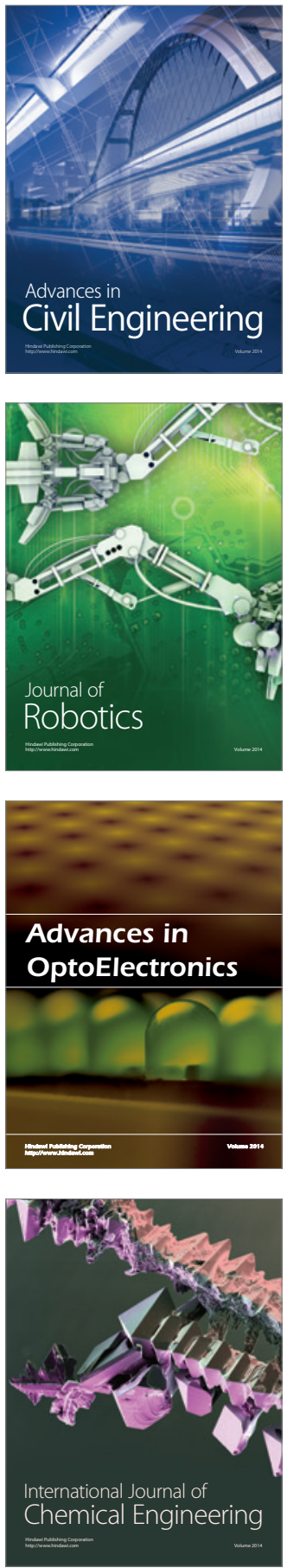

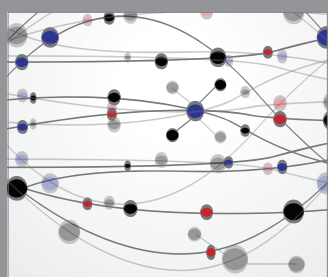

The Scientific World Journal

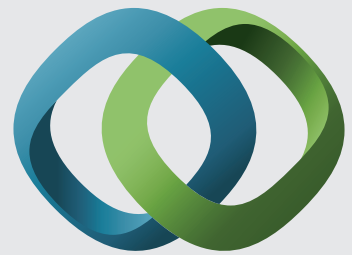

\section{Hindawi}

Submit your manuscripts at

http://www.hindawi.com
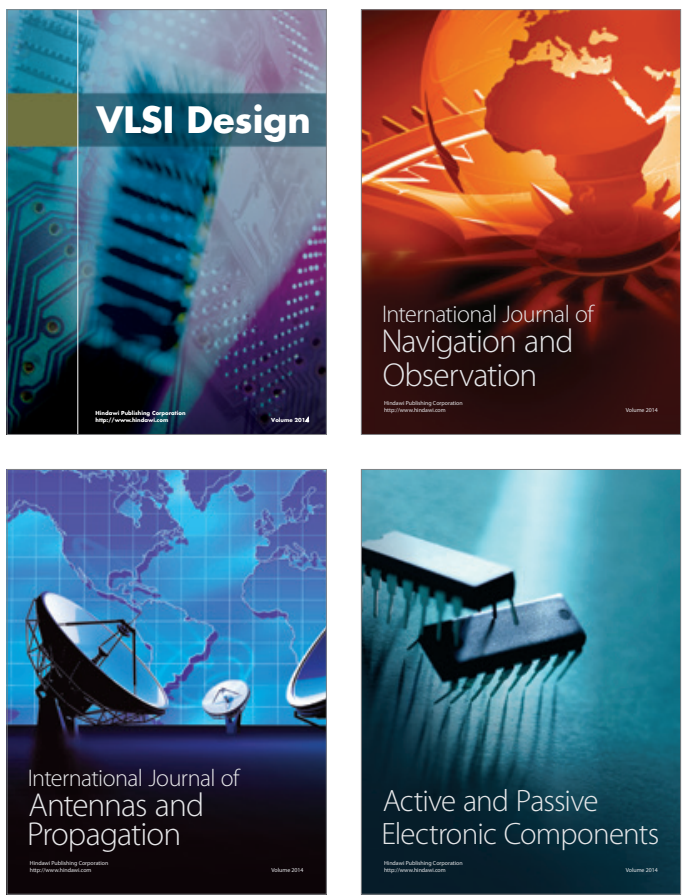
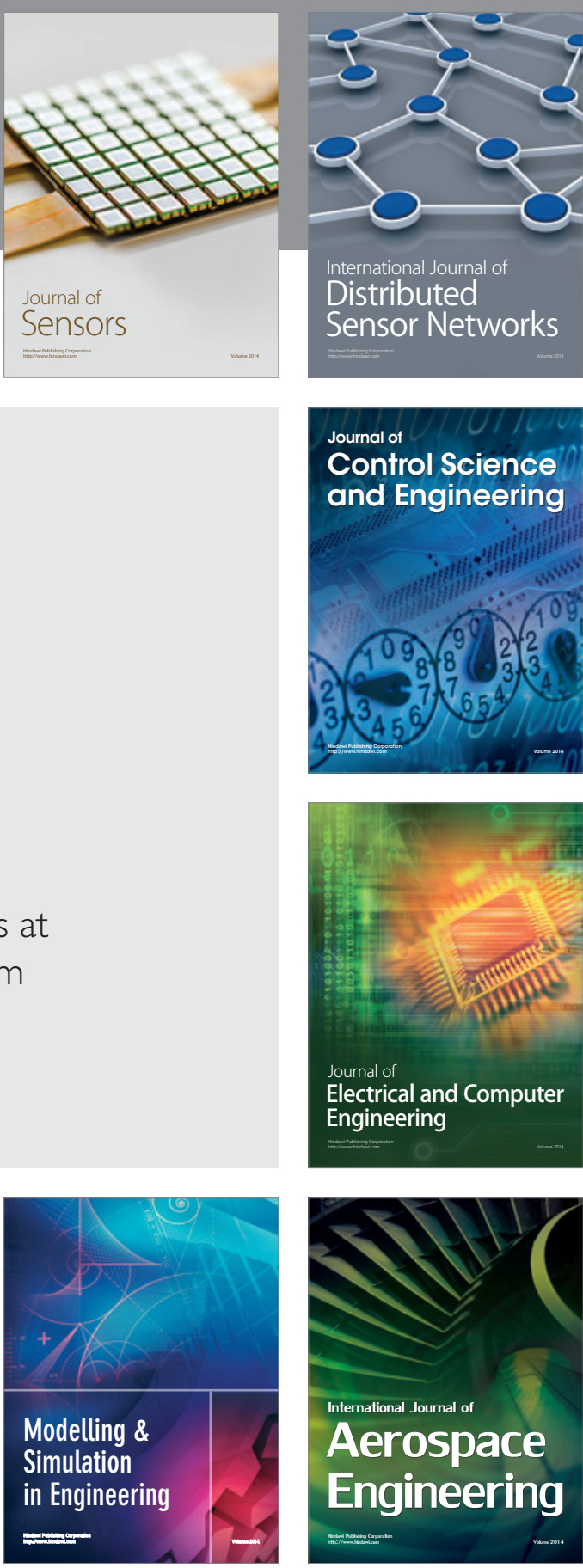

International Journal of

Distributed

Sensor Networks

Journal of

Control Science

and Engineering
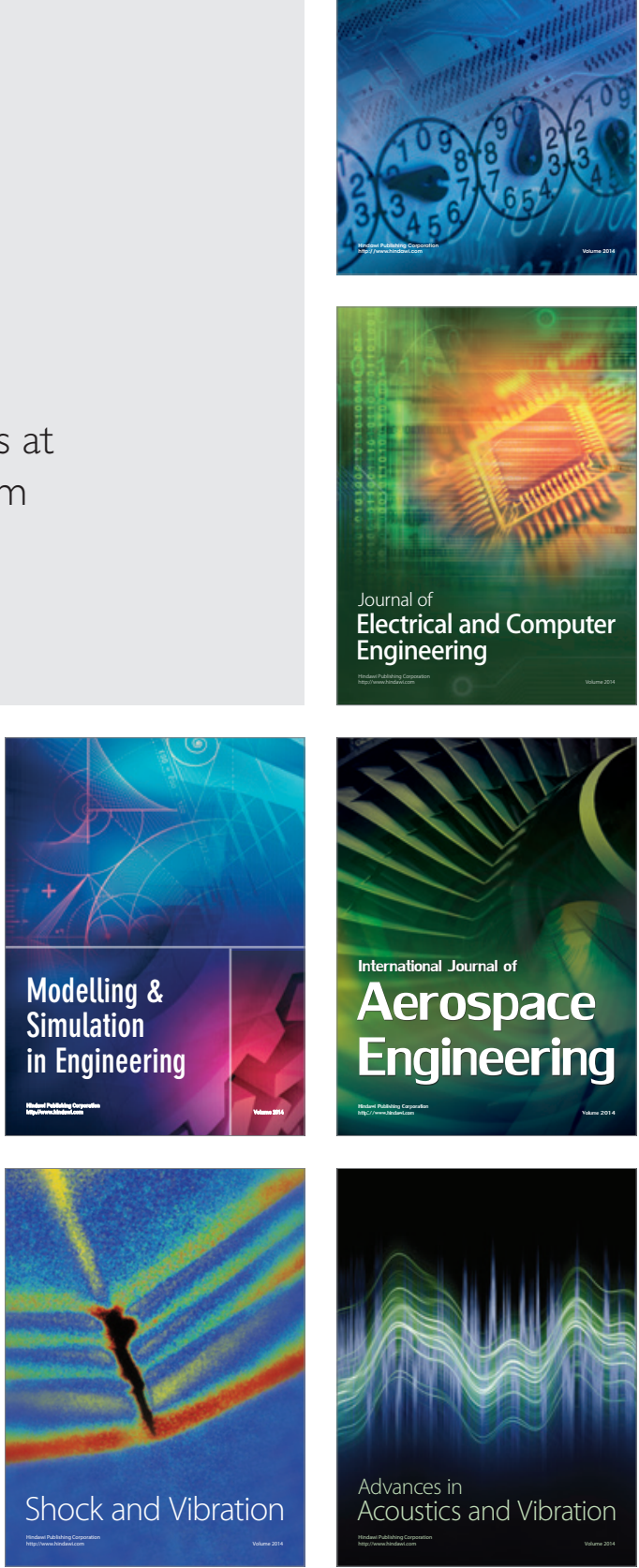